Research Article

\title{
An Improved Prediction Method of Soil-Water Characteristic Curve by Geometrical Derivation and Empirical Equation
}

\author{
Jie Zhou (D), ${ }^{1,2}$ Junjie Ren ${ }^{D},{ }^{1}$ and Zeyao $\mathbf{L i}^{3}$ \\ ${ }^{1}$ Department of Geotechnical Engineering, Tongii University, Shanghai 200092, China \\ ${ }^{2}$ Key Laboratory of Geotechnical and Underground Engineering of Ministry of Education, Tongji University, \\ Shanghai 200092, China \\ ${ }^{3}$ China Construction Second Engineering Bureau Co., Ltd., Beijing 100074, China \\ Correspondence should be addressed to Jie Zhou; zhoujie1001@tongji.edu.cn and Junjie Ren; renjunjie@tongji.edu.cn
}

Received 9 March 2021; Revised 15 May 2021; Accepted 8 June 2021; Published 17 June 2021

Academic Editor: Paolo Crippa

Copyright ( $\odot 2021$ Jie Zhou et al. This is an open access article distributed under the Creative Commons Attribution License, which permits unrestricted use, distribution, and reproduction in any medium, provided the original work is properly cited.

\begin{abstract}
Much attention has been paid on the soil-water characteristic curve (SWCC) during decades because it plays great roles in unsaturated soil mechanics. However, it is time-consuming and costly to obtain a series of entire saturation-suction data by experiments. The curves acquired by directly fitting empirical equations to limited experimental data are greatly different from the actual SWCC, and the relevant soil parameters obtained by inaccurate curve are also incorrect. Thus, an improved prediction method for more accurate entire SWCC was established. This novel method was based on the analysis of shape characteristics of SWCC with three critical points $S, C_{1}$, and $C_{2}$ under the hypothesis of geometrical symmetric relation. The theoretical computation was specifically deduced under conventional Gardner, VG, and FX models, respectively, and then inferred on different soil types of 45 collected SWCC datasets. This geometrical symmetric relation exhibited well in all these three conventional empirical equations, especially in Gardner equation. Finally, a series of filer paper tests on sand, silt, and clay were also carried out to acquire entire SWCC curve for the verification and evaluation of the proposed geometrical method. Results show that this improved prediction method effectively decreases deviation resulting from directly fitting empirical equations to limited data of wide types of soils. The averaged improvement was larger under VG equation than under Gardner and FX equation. It proved that the accuracy of predicting greatly depends on the shape characteristic point of maximum curve curvature (point $C_{2}$ ), other than the number of points. This research provides a novel computation method to improve prediction accuracy even under relative less experimental data.
\end{abstract}

\section{Introduction}

Most of the sedimentary soils widely distributed on the surface belong to unsaturated soils. With the acceleration of human development, more and more engineering practices are related to unsaturated soils, such as the rainfall-induced slope failures, construction about the road and railway subgrades [1], and even the realization of "sponge cities" [2]. Since the soil-water characteristic curve (SWCC) is used as the basis for the prediction of other unsaturated soil parameters, such as the permeability $[3,4]$, shear-strength functions [5], and diffusion coefficient [6], consequently, it is important to have a reasonably accurate characterization of soil-water characteristic curve. And a great number of research studies have focused on the problem about the acquisition of SWCC.

There are two common methods to obtain an entire SWCC experimental dataset. The first method is to directly measure suction through complex and time-consuming experiments. Actually, the pressure plate method is commonly used in the suction measurement of unsaturated soils [7], but the maximum measurement range of this method only can reach $2000 \mathrm{kPa}$ [8], which is not enough for the soil that has a great quantity of fine particles, especially for clay. Other conventional experimental methods such as Tempe cell, solution method [9], filter paper method, and axis translation method are tedious and have narrow measurement range. Some monitors could also be used to 
simultaneously measure soil suction in the model test. Recently, some of newer equipment for determination of SWCC comprise HYPROP, small-scale centrifuge, and dewpoint chilled mirror $[10,11]$. However, each technique has its own limitation in terms of suction. Sometimes, multiple measurement methods are used in combination to acquire an entire SWCC. Consequently, the excessive costs associated with direct measurement of SWCC have encouraged the pursuit of a great quantities of indirect methods to acquiring SWCC based on some empirical relationship and statistical regularity of known soil parameters or limited experimental data, including pedotransfer functions [12], physical-empirical equation [13, 14], fractal equation $[15,16]$, and empirical formula method [17]. In order to get more accurate properties of SWCC, these methods are usually combined with each other $[18,19]$. Additionally, the machine learning or intelligent algorithms are also applied with these methods [20,21].

Besides, considering the relation between the grain-size distribution and SWCC [22-24], some equations can be used to estimate unimodal SWCC with unimodal grain-size distribution $[11,25]$. Pore size distribution function (PSDF) and volumetric shrinkage curve (VSC) also play an important role in estimating SWCC. Fredlund and Xing [26] proposed the SWCC equation by integrating the assumed pore size distribution function. The PSDF also had a significant effect on the saturated coefficient of permeability for sandy soils. The volumetric shrinkage curve (VSC) is commonly used to convert the SWCC in the form of gravimetric water content (w-SWCC) into a curve that is in the form of degree of saturation (S-SWCC) [27]. Lin and Cerato [28] showed that the VSC bears a relationship to the soil-water characteristic curve during drying from a nearsaturated condition. Zhai et al. [29] put forward a framework used to measured w-SWCCs, and the VSC of soil in a loose condition is used as the input information for the estimation of the w-SWCCs of soil under different void ratios.

Because of its wide application and the simplicity of the calculation process, the empirical equation method has become the most common method for estimating SWCC. The common empirical equations that have been proposed include Gardner equation [30], van Genuchten equation (VG equation) [17], Fredlund and Xing equation (FX equation) [31], and Brooks-Corey equation [32]. Recently, some new equations were put forward. Considering the existence of bimodal SWCC and the limitation of conventional equations, Wijaya and Leong [33] proposed a new equation for both unimodal and bimodal SWCCs. However, there is an evident problem that final fitting curves would greatly deviate from the actual SWCC when directly fitting empirical equation to limited data acquired by limitation of suction measurement range of the frequently used suction measure method (Figure 1). Siller and Fredlund [35] stated that the lowest measured water contents and soil suctions appear to influence the magnitude of the residual water content. The fitting routine tends to overestimate the residual water content if the experimental data do not extend well into the zone of desaturation. Consequently, the important values of unsaturated soil predicted by the incorrect SWCC also greatly differ from

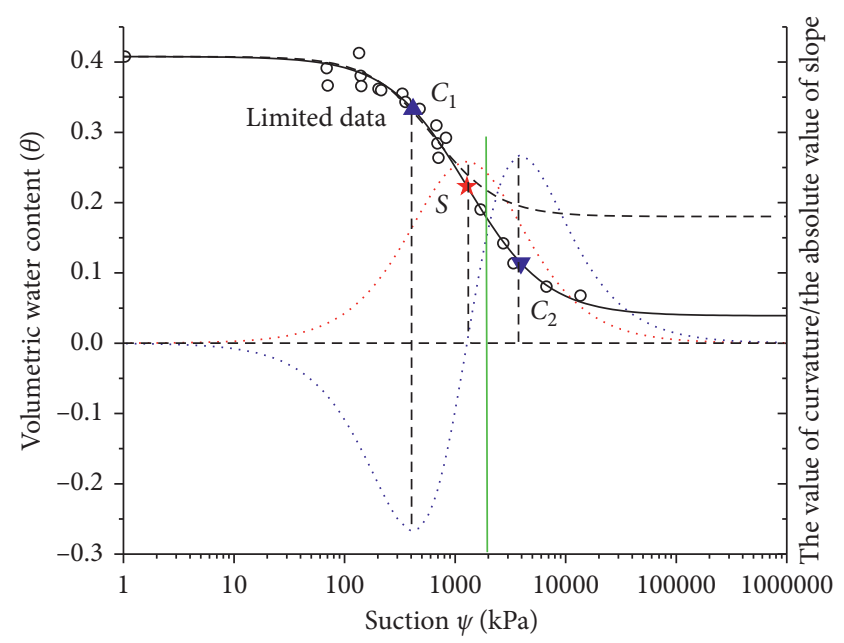

- Experimental data

— SWCC acquired by fitting to Gardner equation

The absolute value of slope of SWCC

..... The value of curvature of SWCC

- - - SWCC acquired by fitting with limited data

$\star \quad$ Point $S$

$\Delta$ Point $C_{1}$

$\nabla$ Point $C_{2}$

FIgURE 1: A typical SWCC and an incorrect SWCC obtained by directly fitting to Gardner equation (data from [34]).

actual values. Moreover, the related design and evaluation results based on the inaccurate values will be unsafe.

However, there are few scholars currently studying the above problems. Wang et al. [36] combined statistical algorithms to predict entire SWCC from the Bayesian perspective, nevertheless, that approach is relatively complicated. Ren et al. [37] proposed a method for estimating SWCC with limited data, but they did not quantitatively testify the feasibility of that method.

This paper tried to acquiring more accurate SWCC from the perspective of geometry. Observing Figure 1, there seems to be a symmetric relation between the point $S$ which is the largest absolute value of slope and two points $C_{1}$ and $C_{2}$ which are two extreme points of curvature on SWCC obtained by Gardner equation in semilogarithmic coordinate. Therefore, in the subsequent part of this paper, the geometrical relation between three points would be discussed, and a geometrical method based on this critical relation for preprocessing limited data before directly fitting with empirical equation was put forward.

\section{Methodology}

2.1. The Geometrical Relationship of $S, C_{1}$, and $C_{2}$ of SWCC under Gardner Equation and Validation. The special geometrical relation is found on the SWCC fitting by Gardner equation; thus, the characteristics of Gardner equation need to be studied. Gardner used a function of three parameters (equation (1)) to describe the soil-water characteristic curve, and it is one of the simplest empirical equations. 


$$
\theta=\theta_{r}+\frac{\theta_{s}-\theta_{r}}{1+(\psi / a)^{b}}
$$

where $\theta$ is the volumetric water content; $\theta_{s}$ is the saturated water content; $\theta_{r}$ is the residual water content as the ratio of the volumetric water gradient to suction approaches zero; $a$ is the fitting parameter related to the air-entry value of value (bubbling pressure); $b$ is the parameter that has relation with desorption rate when the matric suction is bigger than the air-entry value of value; and $\psi$ is the suction of soil, $\mathrm{kPa}$.

Considering the possible geometrical symmetry of three points $S, C_{1}$, and $C_{2}$ which have specific mathematical significance on SWCC in semilogarithmic coordinate, theoretical derivation and checking calculation of substantial datasets were done to prove whether this relation exists.

Firstly, a great number of SWCC datasets of different type of soils (sand, silt, and clay) have been collected to do numerical calculation in order to qualitatively prove that assumption is supported by a quantity of practical experimental data. Every parameter in equation (1) and the suction value of three points are displayed in Table 1 , and the value of $\alpha$ and $\beta$ (equations (2) and (3)) is used to judge the geometrical relation between three points (Table 2). The calculation results of 45 datasets show that $\psi_{s}$ is just equal with $a$, and the values of $\alpha$ and $\beta$ in all datasets are 1 , which means the symmetric relation between the point $S$ and two points $C_{1}$ and $C_{2}$ may exist.

$$
\begin{gathered}
\alpha=\frac{\theta\left(\psi_{S}\right)-\theta\left(\psi_{C_{2}}\right)}{\theta\left(\psi_{C_{1}}\right)-\theta\left(\psi_{S}\right)} \\
\beta=\frac{\log \left(\psi_{C_{2}}\right)-\log \left(\psi_{S}\right)}{\log \left(\psi_{S}\right)-\log \left(\psi_{C_{1}}\right)} .
\end{gathered}
$$

Although the possible relation between three points have been testified by actual data, a series of mathematical derivations also are needed in order to completely and truly prove that geometrical symmetric relation. Thus, the curves of absolute value of slope in semilogarithmic coordinate can be acquired by the following equation:

$$
\begin{aligned}
\left|\dot{\theta}(\psi)_{\log }\right| & =|\dot{\theta}(\psi) \cdot \ln (10) \cdot \psi| \\
& ==\frac{b\left(\theta_{s}-\theta_{r}\right)(\psi / a)^{b-1}}{a\left(1+(\psi / a)^{b}\right)^{2}} \cdot \ln (10) \cdot \psi,
\end{aligned}
$$

and the point $S\left(\psi_{S}, \theta\left(\psi_{S}\right)\right)$ is the extreme point of the curves of absolute value of slope in semilogarithmic that can be derived when the second derivation of $\theta(\psi)$ (equation (5)) is zero.

$$
\ddot{\theta}(\psi)_{\log }=\psi \cdot(\ln (10))^{2} \cdot(\ddot{\theta}(\psi) \cdot \psi+\dot{\theta}(\psi))=-\frac{b^{2}\left(\theta_{s}-\theta_{r}\right)(\psi / a)^{b}\left(-1+(\psi / a)^{b}\right)(\ln (10))^{2}}{\left(1+(\psi / a)^{b}\right)^{3}} .
$$

It is obvious that $\ddot{\theta}(\psi)_{\log }$ achieves zero when $\psi=a$, so the location of point $S\left(\psi_{S}, \theta\left(\psi_{S}\right)\right)$ can be determined as $\left(a, \theta_{s}+\theta_{r} / 2\right)$. Then, the expression of curvature of SWCC in semilogarithmic coordinate can also be defined as the following equation:

$$
k(\psi)=\frac{\ddot{\theta}(\psi)_{\log }}{\left(1+\dot{\theta}(\psi)_{\log }^{2}\right)^{1.5}}=\frac{b^{2}\left(\theta_{s}-\theta_{r}\right)(\psi / a)^{b}\left(-1+(\psi / a)^{b}\right)(\ln (10))^{2}\left(1+(\psi / a)^{b}\right)^{3}}{\left(\left(1+(\psi / a)^{b}\right)^{4}+b^{2}\left(\theta_{s}-\theta_{r}\right)^{2}(\psi / a)^{2 b}(\ln (10))^{2}\right)^{1.5}} .
$$

The points $C_{1}$ and $C_{2}$ are two extreme points of curvature on SWCC in semilogarithmic coordinate; consequently, the points meet the conditions that $\dot{k}\left(\psi_{C_{1}}\right)_{\log }=0$ or $\dot{k}\left(\psi_{C_{2}}\right)_{\log }=0$. Although it is difficult to find all the analytic solution of $\dot{k}(\psi)_{\log }=0$, two solutions $\psi_{C_{1}}=$ $(2-\sqrt{3})^{1 / b} a \cdot t$ and $\psi_{C_{2}}=(2+\sqrt{3})^{(1 / b)} a \cdot 1 / t$ can be found out, where $t$ is a complicate function about $b, \theta_{s}$, and $\theta_{r}$. Thus, the points $C_{1}$ and $C_{2}$ can be determined as $C_{1}\left((2-\sqrt{3})^{(1 / b)} a \cdot t, \theta_{s}+\left(\theta_{s}-\theta_{r}\right) /\left(1+(2-\sqrt{3}) \cdot t^{b}\right)\right)$ and $C_{2}\left((2+\sqrt{3})^{(1 / b)} a \cdot 1 / t, \theta_{r}+\left(\theta_{s}-\theta_{r}\right) /\left(1+(2+\sqrt{3}) \cdot t^{-b}\right)\right)$. Then, the symmetric relation between the point $S$ and points $C_{1}$ and $C_{2}$ in semilogarithmic coordinate can be verified by equations (7) and (8). Plugged the specific coordinates of point $S$ and points $C_{1}$ and $C_{2}$ acquired above into equations (7) and (8), and it was found that those equalities held.

$\theta_{r}$ of FX equation can be acquired by the equation $\theta=$ $\theta_{r}+\left(\theta_{s}-\theta_{r}\right) /\left(\left\{\ln \left[e+(\psi / a)^{b}\right]\right\}^{c}\right)[56]$.

$$
\begin{aligned}
& \log \psi_{C_{1}}+\log \psi_{C_{2}}=2 \log \psi_{S} \Rightarrow \psi_{C_{1}} \cdot \psi_{C_{2}}=\psi_{S}^{2}, \\
& \theta\left(\psi_{C_{1}}\right)+\theta\left(\psi_{C_{2}}\right)=2 \theta\left(\psi_{S}\right) .
\end{aligned}
$$

Through the above deduction, the symmetric relation between three points can be theoretically proved. In conclusion, the symmetric relation between point $C_{2}$ and points $C_{1}$ 


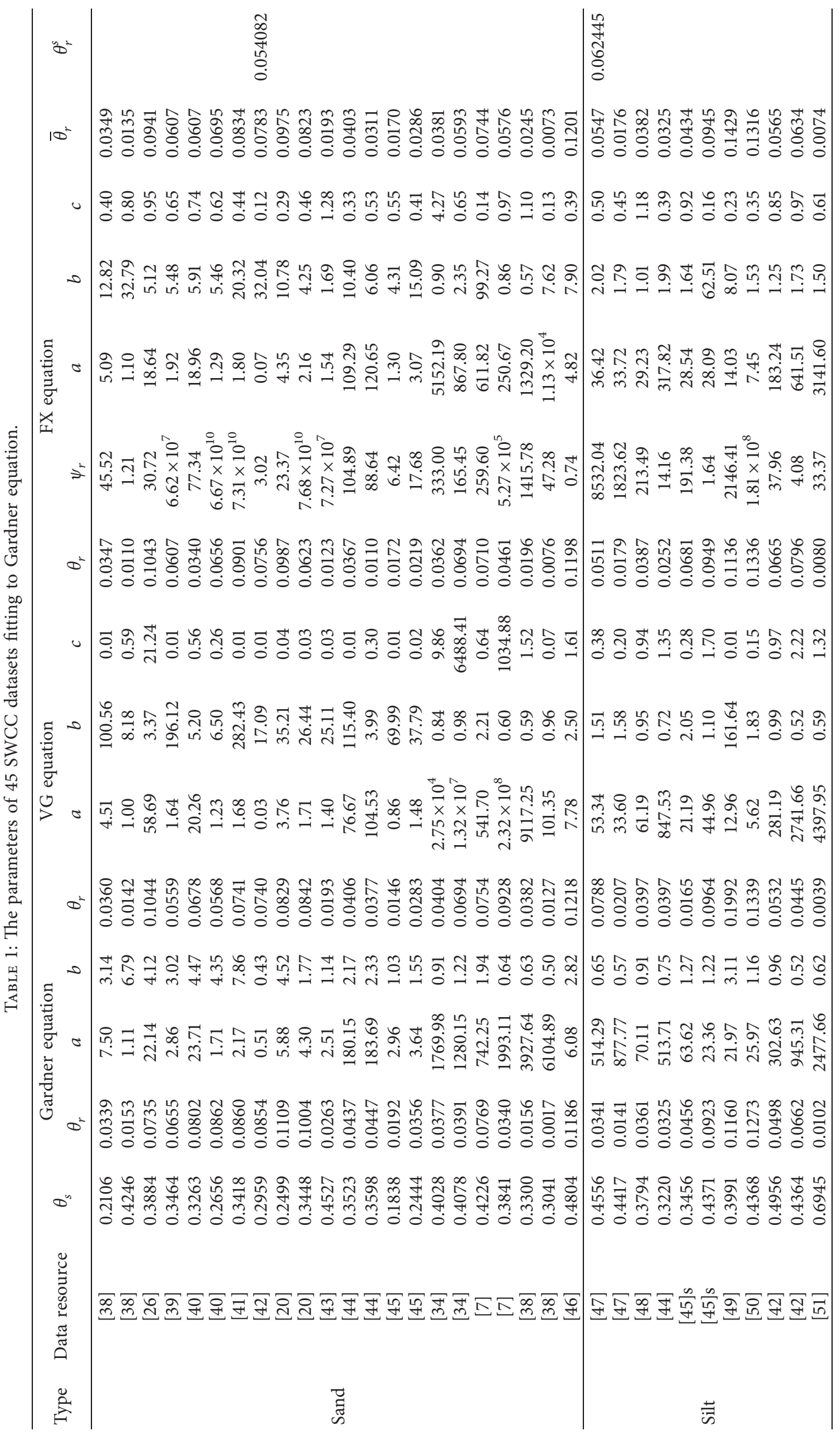




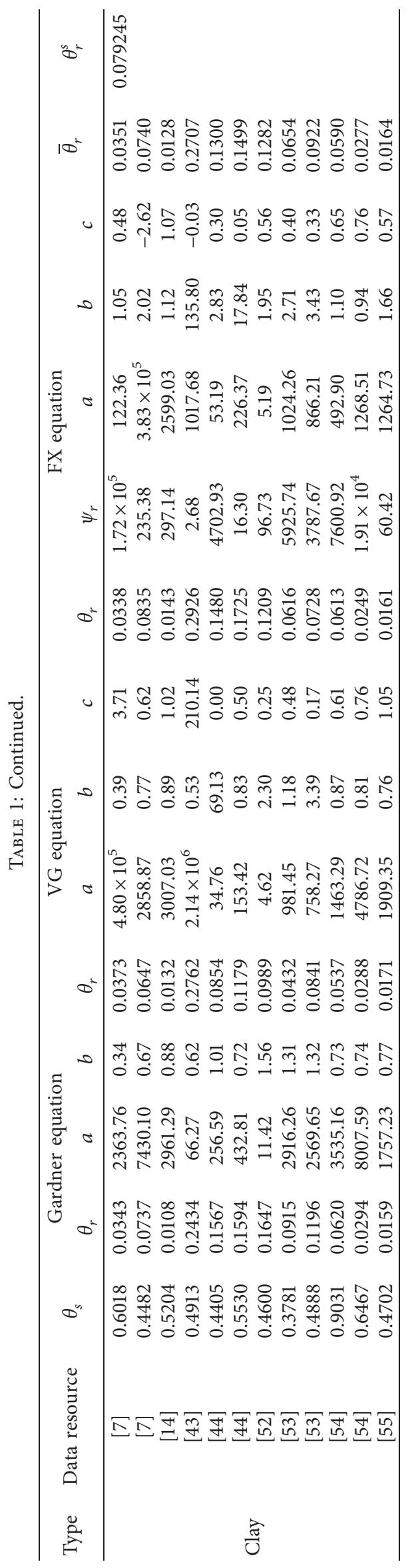


TABle 2: The $\psi$ of point $S, C_{1}$, and $C_{2}$ of 45 SWCC datasets fitting to Gardner equation, VG equation, and FX equation.

\begin{tabular}{|c|c|c|c|c|c|c|c|c|c|c|c|c|c|c|c|c|}
\hline \multirow{2}{*}{ Type } & \multirow{2}{*}{$\begin{array}{l}\text { Data } \\
\text { resource }\end{array}$} & \multicolumn{5}{|c|}{ Gardner equation } & \multicolumn{5}{|c|}{ VG equation } & \multicolumn{5}{|c|}{ FX equation } \\
\hline & & $\psi_{S}$ & $\psi_{C_{1}}$ & $\psi_{C_{2}}$ & $\alpha$ & $\beta$ & $\psi_{S}$ & $\psi_{C_{1}}$ & $\psi_{C_{2}}$ & $\alpha$ & $\beta$ & $\psi_{S}$ & $\psi_{C_{1}}$ & $\psi_{C_{2}}$ & $\alpha$ & $\beta$ \\
\hline \multirow{22}{*}{ Sand } & [38] & 7.50 & 4.81 & 11.69 & 1.00 & 1.00 & 4.70 & 4.50 & 4.95 & 1.34 & 1.17 & 5.62 & 4.86 & 6.44 & 1.01 & 0.94 \\
\hline & [38] & 1.11 & 0.80 & 1.54 & 1.00 & 1.00 & & & & & & & 0.96 & & 1.30 & 0.92 \\
\hline & [26] & 22.14 & 14.82 & 33.09 & 1.00 & 1.00 & 23.69 & 15.96 & 37.28 & 0.92 & 1.15 & 21.66 & 15.26 & 30.50 & 1.02 & \\
\hline & [39] & 2.86 & 1.75 & 4.68 & 1.00 & 1.00 & 2.86 & 2.04 & 5.08 & 0.93 & 1.70 & 2.32 & 1.68 & 3.16 & 1.01 & 0.95 \\
\hline & [40] & 23.71 & 16.67 & 33.74 & 1.00 & 1.00 & 22.66 & 16.09 & 32.42 & 1.07 & 1.05 & 22.26 & 16.50 & 29.69 & 1.01 & 0.96 \\
\hline & [40] & 1.71 & 1.22 & 2.39 & 1.00 & 1.00 & 1.51 & 1.10 & 2.10 & 1.11 & 1.05 & 1.57 & 1.15 & 2.09 & 0.99 & 0.94 \\
\hline & [41] & 2.17 & 1.69 & 2.78 & 1.00 & 1.00 & 1.91 & 1.67 & 2.31 & 0.98 & 1.47 & 1.91 & 1.68 & 2.20 & 1.23 & 1.15 \\
\hline & [42] & 0.51 & 0.02 & 10.92 & 1.00 & 1.00 & 0.49 & 0.07 & 6.82 & 0.83 & 1.39 & 0.08 & 0.07 & 0.08 & 1.04 & 0.94 \\
\hline & [20] & 5.88 & 4.30 & 8.03 & 1.00 & 1.00 & 4.73 & 3.74 & 6.61 & 1.10 & 1.42 & 4.5 & 4.18 & 5.77 & 0.98 & 0.92 \\
\hline & [20] & 4.30 & 1.99 & 9.28 & 1.00 & 1.00 & 3.95 & 1.69 & 8.89 & 0.52 & 0.96 & 3.8 & 1.93 & & 0.71 & 1.23 \\
\hline & [43] & 2.51 & 0.75 & 8.35 & 1.00 & 1.00 & & & & 1.77 & 1.38 & & 0.92 & & 0.98 & 0.95 \\
\hline & [44] & 180.15 & 94.04 & 345 & 1.00 & 1.00 & & 80.12 & & 0.89 & 1.11 & & & & 02 & 0.95 \\
\hline & [44] & 3.69 & 98.81 & 341.48 & 1.00 & 1.00 & & 85.91 & & & & & & & & \\
\hline & [45] & 96 & 0.82 & 10.71 & & 1.00 & & & & & & & & & & 1.30 \\
\hline & [45] & & & & & & & & & & & & & & 05 & 0.98 \\
\hline & [34] & 1769.98 & 400. & & 1.00 & 1.00 & 178 & 511 & & 0.93 & 0.98 & & 419.46 & & .90 & 0.92 \\
\hline & [34] & 30.15 & 4 & & 1.00 & 1.00 & 170 & 61 & & 0.91 & 0.98 & & 624.03 & & .01 & 0.99 \\
\hline & [7] & 2.25 & 356.39 & & 1.00 & 1.00 & 679 & 33.14 & 1396 & 1.00 & 1.01 & & 469 & & 0.74 & 1.66 \\
\hline & {$[7]$} & 93.11 & 249.91 & $1.59 \times 10^{4}$ & 1.00 & 1.00 & 2318.54 & 458.22 & $1.16 \times 10^{4}$ & 0.93 & 0.99 & 632 & 115.83 & 2923.60 & 0.94 & 0.90 \\
\hline & [38] & 927.64 & 470.87 & $3.28 \times 10^{4}$ & 1.00 & 1.00 & 4914.27 & 619.07 & $3.99 \times 10^{4}$ & 0.95 & 1.00 & 3532.32 & 500.16 & $2.55 \times 10^{4}$ & 1.03 & 1.01 \\
\hline & [38] & 6104.89 & 431.30 & $8.64 \times 10^{4}$ & 1.00 & 1.00 & 6651.27 & 482.94 & $8.31 \times 10^{4}$ & 0.88 & 0.96 & 6488.40 & 472.30 & $8.47 \times 10^{4}$ & 1.31 & 0.98 \\
\hline & [46] & 6.08 & 3.52 & 10.52 & 1.00 & 1.00 & 6.44 & 3.64 & 11.19 & 0.96 & 0.97 & 5.63 & 4.40 & 7.16 & 1.04 & 0.98 \\
\hline \multirow{11}{*}{ Silt } & [47] & 420 & 65.78 & 4020.82 & 1.00 & 1.00 & 101.68 & 32.10 & & 1.05 & 1.01 & & 29.16 & & 0.96 & 0.91 \\
\hline & [47] & 7.77 & 84.28 & & 1.00 & 1.00 & 3.37 & 4.84 & & 1.08 & 1.01 & & 26.90 & & 1.02 & 1.87 \\
\hline & [48] & 70.11 & 16.15 & 2437 & 1.00 & 1.00 & 65. & 15.57 & 75.97 & 1.00 & 1.00 & 57.10 & 13.74 & & 0.98 & 0.95 \\
\hline & [44] & 513.71 & 87.46 & 3017.35 & 1.00 & 1.00 & 549.34 & 96.48 & 3123.20 & 1.00 & 1.00 & & 103.32 & & 1.13 & 1.16 \\
\hline & [45] & 63.62 & 21.83 & 185.38 & 1.00 & 1.00 & 39.56 & 15.63 & 101.32 & 1.07 & 1.01 & 47.0 & 18.84 & & 0.96 & 0.92 \\
\hline & [45] & 323 & 7.65 & 71.37 & 1.00 & 1.00 & & 9.01 & 84.62 & 0.97 & 0.99 & & 27.44 & 30.67 & 1.44 & 1.33 \\
\hline & [49] & & 19.55 & & 1.00 & 1.00 & & 12.94 & & 1.41 & 1.20 & & 13.38 & & 0.98 & 0.91 \\
\hline & [50] & & & & & & & & & & & & & & 96 & 0.90 \\
\hline & [42] & & & & & & & & & & & & & & & \\
\hline & [42] & & 73.25 & & 1.00 & 1.0 & & & & & & & & & 08 & 1.11 \\
\hline & [51] & 177.66 & 270.50 & $2.27 \times 10^{4}$ & 1.00 & 1.00 & 3137.80 & 189.46 & $2.80 \times 10^{4}$ & 0.79 & 0.78 & 2012.34 & 135.66 & $2.16 \times 10^{4}$ & 1.20 & 0.88 \\
\hline \multirow{12}{*}{ Clay } & [7] & 363.75 & 50.31 & $1.11 \times 10^{5}$ & 1.00 & 1.00 & $1.61 \times 10^{4}$ & 943.47 & $2.69 \times 10^{5}$ & 0.96 & 0.99 & 2385.66 & 73.03 & $1.10 \times 10^{5}$ & 0.78 & 1.10 \\
\hline & [7] & 7430.10 & 1014.25 & & 1.00 & 1.00 & 5347.42 & 765.62 & & 1.02 & 1.00 & $1.40 \times 10^{4}$ & 232.70 & $2.53 \times 10^{5}$ & 0.67 & 0.71 \\
\hline & [14] & 2961.28 & 629.33 & $1.39 \times 10^{4}$ & 1.00 & 1.00 & 2945.55 & & & & 1.00 & & & $1.15 \times 10^{4}$ & 0.90 & 0.88 \\
\hline & [43] & & & & & & & & & & & & & & 07 & \\
\hline & {$[44]$} & 256.59 & 67.82 & 970.84 & 1.00 & 1.00 & & & & 0.72 & 1.06 & & & & 0.87 & \\
\hline & [44] & 432.81 & 67.72 & 2766.34 & 1.00 & 1.00 & 233.85 & 25.60 & 2179.71 & 1.26 & 1.01 & 248.25 & 223.76 & 272.49 & 0.94 & 0.90 \\
\hline & [52] & 11.42 & 4.74 & 27.53 & 1.00 & 1.00 & 10.64 & 4.64 & 25.77 & 0.94 & 1.07 & 9.26 & 4.03 & 19.43 & 0.94 & 0.89 \\
\hline & [53] & 2916.26 & 1035.33 & 8214.35 & 1.00 & 1.00 & 2694.63 & 967.33 & 7548.71 & 0.88 & 1.01 & 2651.25 & 978.06 & 7808.75 & 0.75 & 1.08 \\
\hline & [53] & 2569.65 & 903.52 & 7308.18 & 1.00 & 1.00 & 2281.71 & 871.06 & 7791.75 & 0.84 & 1.28 & 2284.17 & 865.65 & 7995.74 & 0.75 & 1.29 \\
\hline & [54] & 3535.16 & 513.19 & $2.44 \times 10^{4}$ & 1.00 & 1.00 & 2560.38 & 419.47 & $1.60 \times 10^{4}$ & 1.03 & 1.01 & 1348.69 & 297.34 & 4066.30 & 0.83 & 0.73 \\
\hline & [54] & 8007.59 & 1254.26 & $5.11 \times 10^{4}$ & 1.00 & 1.00 & 6715.74 & 1105.24 & $4.11 \times 10^{4}$ & 1.01 & 1.00 & 4612.57 & 733.92 & $4.04 \times 10^{4}$ & 1.23 & 1.18 \\
\hline & [55] & 1757.23 & 304.32 & $1.01 \times 10^{4}$ & 1.00 & 1.00 & 1877.85 & 325.12 & $1.08 \times 10^{4}$ & 0.98 & 1.00 & 1836.05 & 349.76 & $1.18 \times 10^{4}$ & 1.06 & 1.12 \\
\hline
\end{tabular}

and $S$ in semilogarithmic coordinate can be quantitatively and qualitatively proved based on numerical checking of 45 SWCC experimental datasets and mathematical derivations. Consequently, the specific position of point $C_{2}$ can be acquired when the points $C_{1}$ and $S$ are known by making use of this relation.

2.2. The Geometrical Relationship of Points $S, C_{1}$, and $C_{2}$ of SWCC under VG Equation and $F X$ Equation. Besides Gardner equation, VG equation put forward by van Genuchten (equation (9)) and FX equation (equation (10)) raised by Fredlund are also the popular empirical equations used to acquire SWCC. Considering the VG equation is one of the most frequently used empirical equations and the FX equation can give the best fit among the equations [56], they are selected to testify whether this graphic symmetric relationship exists in other equations.

$$
\begin{aligned}
\theta & =\theta_{r}+\frac{\theta_{s}-\theta_{r}}{\left[1+(\psi / a)^{b}\right]^{c}} \\
\theta & =\left[1-\frac{\ln \left(1+\psi / \psi_{r}\right)}{\ln \left(1+1000000 / \psi_{r}\right)}\right] \frac{\theta_{s}}{\left\{\ln \left[e+(\psi / a)^{b}\right]\right\}^{c}} \\
C(\psi) & =1-\frac{\ln \left(1+\psi / \psi_{r}\right)}{\ln \left(1+1000000 / \psi_{r}\right)}
\end{aligned}
$$


The same calculations were done to 45 selected experimental datasets in order to find three special points $S, C_{1}$, and $C_{2}$ whether have the same relation on the curve fitting to the VG equation and FX equation. $\psi$ of points $S, C_{1}$, and $C_{2}$ is shown in Table 2, and the value of $\alpha$ and $\beta$ (equations (2) and (3)) is also used to judge the geometrical symmetric relation of three points. It is found that $\alpha$ and $\beta$ of Gardner equation and FX equation are not exactly equal to 1 , but they are still very close to 1 . In consideration of the fact that these empirical equations are all used to fit with the same dataset of discrete points, despite their slightly different forms, the curves acquired are roughly same. Thus, the positions of points $S, C_{1}$, and $C_{2}$ on the curves obtained by VG and FX equations are similar to those on the curve obtained by Gardner equation. In conclusion, the graphic symmetric relation between three special points $S, C_{1}$, and $C_{2}$ can also be considered generally valid on the curves fitting by VG equation and FX equation.

2.3. The Physical Meaning of Points $S, C_{1}$, and $C_{2}$. Although the mathematical significance and geometrical symmetric relation of three points $S, C_{1}$, and $C_{2}$ have been proved by theoretical derivation and checking calculation of substantial datasets, the specific physical meaning of these points is also needed to be discussed. Some researchers have already studied SWCC from the geometrical perspective. Siller and Fredlund [35] used two points of extreme values of curvature to divide SWCC into three zones (capillary saturation zone, funicular zone, and zone of residual saturation). Fredlund and Xing [26] put forward a geometric solution to determine parameters $a, b$, and $c$ in equation (12) by drawing a tangent line through point $S$ and, respectively, intersecting the approximate straight lines of low-suction part (capillary saturation zone) and high suction part (zone of residual saturation) of SWCC. They considered that two points $S_{1}$ and $S_{2}$ related with the air-entry value $\psi_{a}$ (the matric suction where air starts to enter the largest pores in the soil) and the residual water content $\theta_{r}$ are the intersection points. However, the points $C_{1}$ and $C_{2}$ put forward in this paper are on the SWCC which are the extreme values of curvature. The points $S_{1}$ and $S_{2}$ are the intersection points of tangent line of point $S$ and lines of low-suction part which are out of SWCC. In view of graph, they are all around the curvy part of SWCC and close to each other (Figure 2). Additionally, the points $C_{1}$ and $C_{2}$ are on the SWCC, so they may have stronger physical connection with SWCC than points $S_{1}$ and $S_{2}$, especially the change of curvature. Therefore, points $C_{1}$ and $C_{2}$ also have relationship with the air-entry value $\psi_{a}$ and the residual water content $\theta_{r}$. The airentry value $\psi_{a}$ and the residual water content $\theta_{r}$ are closely associated with the mineral composition, pore structure, and dense state; among them, the mineral composition and pore structure are the basic factors. Moreover, these two points are crucial for determining the position and shape of SWCC because of their important mathematical meaning. In other words, SWCC is a typical sigmoid curve; once the locations of mutation point of curvature are confirmed, the rough shape and position of SWCC can be obtained.
The point $S$ is the inflection point of SWCC (the point is largest absolute value of slope), from the perspective of pore size distribution; it corresponds to the point with the maximum value of frequency in the pore size distribution curve [57]. Because of the log-normal distribution of pore size of most soils, the maximum value of frequency in the pore size distribution curve can be considered as the mean pore size of the soil sample [37]. Besides this, Ren and Santamaina [58] and Ren et al. [59] mentioned that the mean pore size can be expressed by void ratio and specific surface area. Therefore, the position of point $S$, void ratio, and specific surface area may have some inner link.

2.4. The Significance of Point $C_{2}$. When the empirical equations are used to fitting available datasets, it is significant to have an effective and precise standard to judge whether datasets can generate accurate outcomes. Leong and Rahardjo [56] mentioned that the data used to obtain SWCC should include points after $\theta_{r}$ which is not directly available value before fitting. Fredlund and Xing [26] considered that the magnitude of $\psi_{r}$ will generally be in the range of 1500 to $3000 \mathrm{kPa}$ but not an exact value of $\psi_{r}$.

According to the above discussion about the physical and geometrical relation between the point $C_{2}$ and value of $\theta_{r}$, this paper desired to quantitatively check whether point $\mathrm{C}_{2}$ is also important to acquiring accurate SWCC. The SWCC datasets of three types of soils were chosen. Then, the half and quarter points of datasets were used to fit to equation (12), which is the empirical equation of low sensitivity according to the analyses carried out by Leong [56]. Moreover, the points before the point $C_{2}$ and the dataset including the point just larger than point $C_{2}$ were also been calculated. Because all the empirical equations are the overparameterized functions (the parameters of the functions are not independent), some different fitting parameter combinations result in the same curves for the same dataset. Thus, equation (13) was used to evaluate the difference between the curves obtained by different datasets, where $f(x)$ and $g(x)$ are two different SWCC suction-saturation equation needed to be compared and $\eta$ is the proximity of the two curves in some extent; the smaller $\eta$ is, the closer the two curves are. The calculating results of different types of soils are shown in Figure 3 and Table 3.

$$
\begin{aligned}
& \theta=\frac{\theta_{s}}{\left\{\ln \left[e+(\psi / a)^{b}\right]\right\}^{c}}, \\
& \eta=\int_{0.01}^{10^{6}}|f(x)-g(x)| d(\log x) .
\end{aligned}
$$

From Figure 3 and Table 3, it was easy to drive a conclusion that curves acquired by half points and a quarter points were almost coincided with the SWCC obtained by original dataset. However, the difference between the curves acquired by the points before point $C_{2}$ and the original SWCC was relatively large. And the gap reduced when the fitting dataset just including the point $C_{2}$. In some occasions, the SWCC obtained by the dataset including point $C_{2}$ is almost similar to the original curve. Therefore, a conclusion 


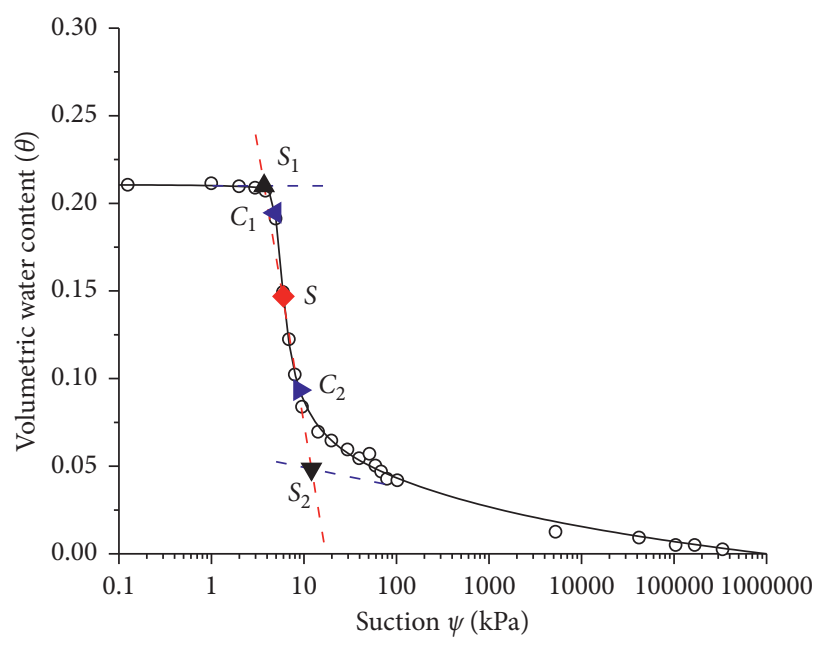

- Experimental data

- SWCC fitting to FX equation

(a)

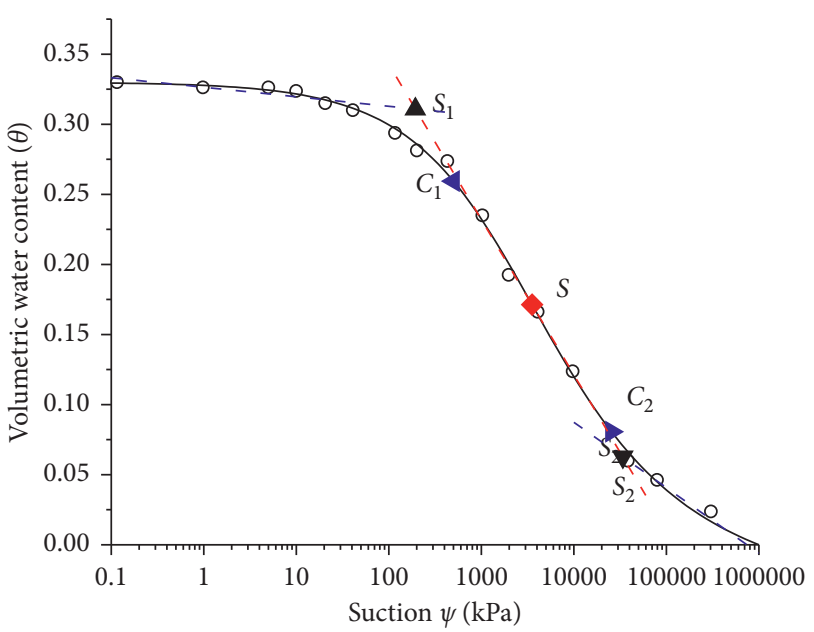

- Experimental data SWCC fitting to FX equation

(b)

Figure 2: The difference between the points $S_{1}$ and $S_{2}$ and points $C_{1}$ and $C_{2}$ (two examples of SWCC acquired by FX equation): (a) sand (data from [38]); (b) silt (data from [38]).
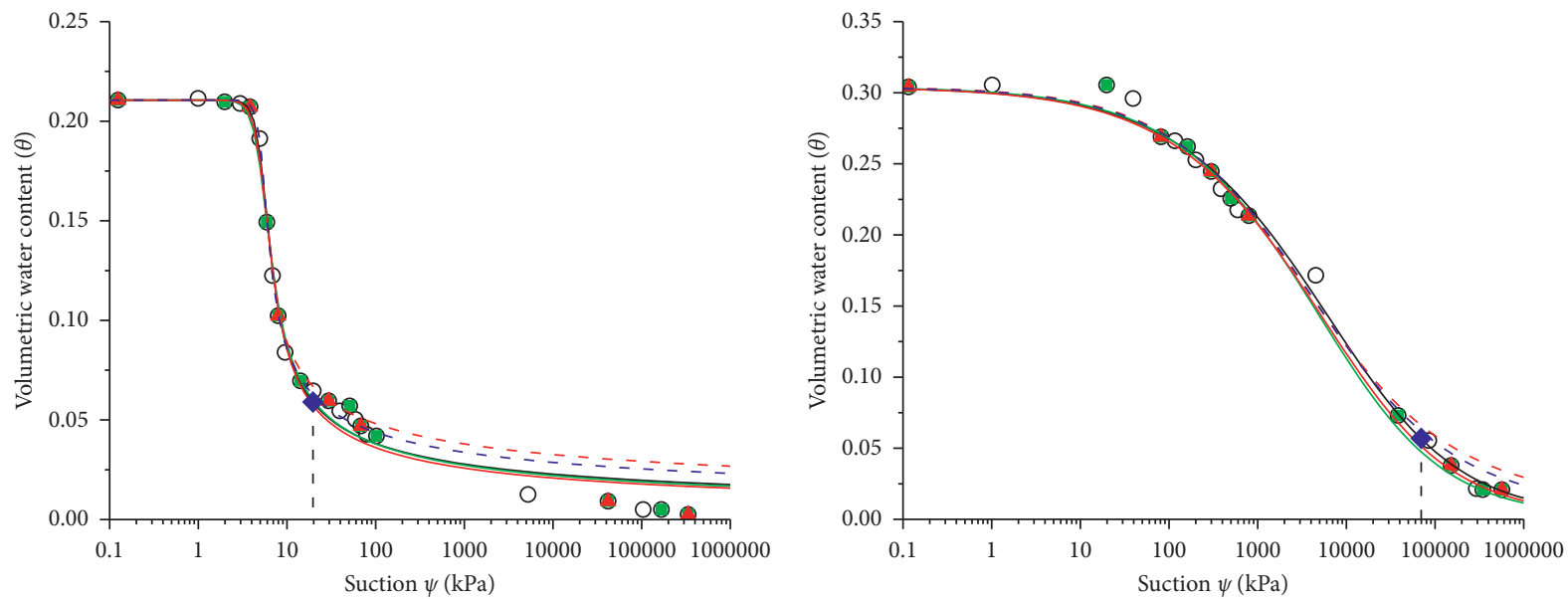

O 24 points (complete)

- 13 points

- 6 points

_ SWCC fitting to 24 points

SWCC fitting to 13 points

- SWCC fitting to 6 points

- $C_{2}$ of complete SWCC

- - - SWCC fitting to points before $C_{2}$

- - - SWCC fitting to points including $C_{2}$

(a)

O 20 points (complete)

- 11 points

- 6 points

_ SWCC fitting to 20 points

- SWCC fitting to 11 points

— SWCC fitting to 6 points

- $C_{2}$ of complete SWCC

- - - SWCC fitting to points before $C_{2}$

- - - SWCC fitting to points including $C_{2}$

(b)

Figure 3: Continued. 


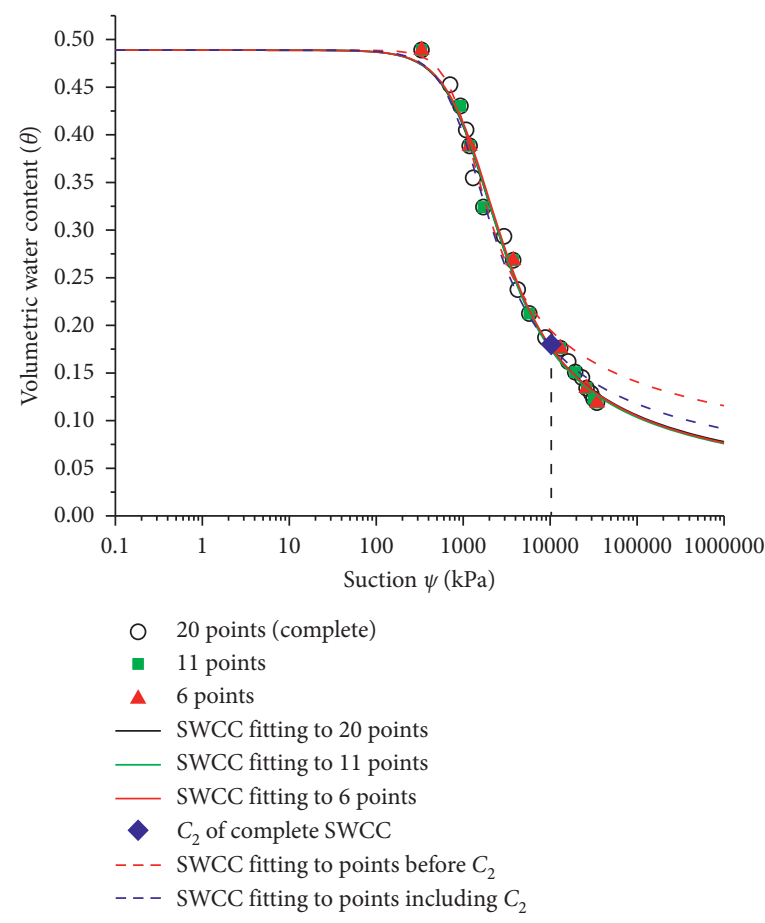

(c)

FIgURE 3: The results fitting to equation (13) with datasets of different situations (a half data, a quarter data, and the data points before point $C_{2}$ ): (a) sand (data from [38]); (b) silt (data from [38]); (c) clay (data from [53]).

TABLE 3: The results of fitting to equation (13) with datasets of different situations.

\begin{tabular}{|c|c|c|c|c|c|}
\hline Soil type & Points situation & $a$ & $b$ & $c$ & $\eta$ \\
\hline \multirow{5}{*}{ Sand [38] } & 24 points & 5.037 & 7.421 & 0.551 & \\
\hline & 13 points & 4.885 & 6.146 & 0.586 & 0.00508 \\
\hline & 6 points & 4.982 & 6.612 & 0.590 & 0.01032 \\
\hline & Before $C_{2}$ & 5.025 & 11.552 & 0.417 & 0.04922 \\
\hline & Including $C_{2}$ & 5.072 & 10.799 & 0.452 & 0.02913 \\
\hline \multirow{5}{*}{ Silt [38] } & 20 points & 10394.203 & 0.480 & 3.354 & \\
\hline & 11 points & 8089.230 & 0.508 & 3.348 & 0.03059 \\
\hline & 6 points & 9028.341 & 0.485 & 3.393 & 0.02031 \\
\hline & Before $C_{2}$ & 2095.411 & 0.547 & 1.880 & 0.02828 \\
\hline & Including $C_{2}$ & 7254.044 & 0.525 & 2.223 & 0.01836 \\
\hline \multirow{5}{*}{ Clay [53] } & 20 points & 1097.902 & 1.756 & 0.740 & \\
\hline & 11 points & 1120.315 & 1.767 & 0.750 & 0.00575 \\
\hline & 6 points & 1149.266 & 1.747 & 0.775 & 0.02988 \\
\hline & Before $C_{2}$ & 878.877 & 2.653 & 0.493 & 0.20576 \\
\hline & Including $C_{2}$ & 903.982 & 2.048 & 0.629 & 0.16672 \\
\hline
\end{tabular}

could be drawn that the accuracy of empirical equations fitting depends on the dataset whether it includes point $C_{2}$ other than the number of points. Then, in this paper, the dataset which is of sigmoid shape and at least reaches the maximum curvature (point $C_{2}$ ) can be regarded as a "entire" SWCC dataset.

2.5. A Geometrical Method for Entire SWCC. As what are discussed above, the experimental datasets sometimes miss the points of part of funicular zone and zone of residual saturation because of the limitation of the range of the measuring instruments. Thus, this paper puts forward a method to predict the position of point $C_{2}$ and point $S$ based on the graphic symmetric relationship of points $S, C_{1}$, and $\mathrm{C}_{2}$ to acquire more accurate SWCC.

Firstly, the first critical point $C_{1}\left(\psi_{C_{1}}, \theta\left(\psi_{C_{1}}\right)\right)$ is the first extreme value of curvature on the SWCC that is obtained by directly fitting empirical equations to limited data. because the upper part of SWCC acquired by fitting to limited dataset is almost coincident with that of actual SWCC. In most cases, the first point of extreme value of curvature $\left(C_{1}\left(\psi_{C_{1}}, \theta\left(\psi_{C_{1}}\right)\right)\right)$ on these two curves is almost the same. The inflection point $S$ on the SWCC of Gardner equation is 
$\left(a, \theta_{s}+\theta_{r} / 2\right)$, and the inflection point $S$ acquired by other empirical equations is very close. Therefore, point $\left(a, \theta_{s}+\right.$ $\left.\theta_{r} / 2\right)$ can be seen as the inflection point $S$ on the SWCC, and $\theta_{s}$ can be easily obtained from the saturated samples. The value of $\theta_{r}$ is closely associated with the soil characteristics, like mineral composition, pore structure, and dense state. In consideration of that, $\theta_{r}$ of different datasets under different empirical equations was calculated (Table 1), and the average values of same dataset under three different empirical equations were gained. Afterwards, these 15 values of different types of soils were also averaged; thus, the statistical values of $\theta_{r}$ of three types of soils were obtained. It was found that these three statistical values of $\theta_{r}$ were in line with the characteristics of different soils that the finer particle size is, the higher values of $\theta_{r}$ is. Consequently, the empirical values of $\theta_{r}$ of sand, silt, and clay were, respectively, chosen as $0.054082,0.062445$, and 0.079245 . The points $S, C_{1}$, and $C_{2}$ are almost in a line, considering the coincidence of the upper part of SWCC acquired from limited dataset and that of actual SWCC; therefore, the line $C_{1}^{\prime} C_{2}^{\prime}$ of the SWCC acquired by limited data almost coincides with the line $C_{1} S C_{2}$ of the actual SWCC. In other words, predicting point $S$ is on the line $C_{1}^{\prime} C_{2}^{\prime}$. Consequently, $\theta\left(\psi_{S}\right)$ could be derived by the empirical $\theta_{r}$ and known $\theta_{s}$ (equation (14)), and the value of $\psi_{S}$ could be gained by the line $C_{1}^{\prime} C_{2}^{\prime}$ and the obtained value of $\theta\left(\psi_{S}\right)$ (equation (15)). Eventually, the point $C_{2}$ could be acquired by predicting point $S$ and known point $C_{1}$ (equations (16) and (17)). Moreover, point $C_{2}$ was added to limited dataset, and the new dataset was fitted to empirical equations to get a more accurate SWCC.

$$
\begin{aligned}
\theta\left(\psi_{S}\right) & =\frac{\left(\theta_{s}+\theta_{r}\right)}{2}, \\
\log \left(\psi_{S}\right) & =\frac{\left(\theta\left(\psi_{C_{2}^{\prime}}\right)-\theta\left(\psi_{S}\right)\right)\left(\log \left(\psi_{C_{2}^{\prime}}\right)-\log \left(\psi_{C_{1}^{\prime}}\right)\right)}{\left(\theta\left(\psi_{C_{1}^{\prime}}\right)-\theta\left(\psi_{C_{2}^{\prime}}\right)\right)}+\log \left(\psi_{C_{2}^{\prime}}\right), \\
\log \left(\psi_{C_{2}}\right) & =2 \log \left(\psi_{S}\right)-\log \left(\psi_{C_{1}}\right), \\
\theta\left(\psi_{C_{2}}\right) & =2 \theta\left(\psi_{S}\right)-\theta\left(\psi_{C_{1}}\right) .
\end{aligned}
$$

However, in some cases, the lowest value of $\theta$ of limited dataset may be lower than the empirical value of $\theta_{r}$ this paper adopted. Then, $\theta\left(\psi_{S}\right)$ could be chosen as $\theta_{s} / 2$. An example shows procedures and processing result (Figure 4), and diagrammatic sketch about specific procedures of this geometrical predicting method is shown in Figure 5.

\section{Materials and Experiment}

3.1. Materials. The soil sample used in this test was remolded soil. Sand, silt, and clay are all configured by forging kaolin and standard sand according to the predetermined mass ratio. Two kinds of particle sizes were used $(0.045 \mathrm{~mm}$ and $0.001 \mathrm{~mm}$ ). Standard sand is made according to the standard named GB/T17671-1999, and the grain diameter ranges from $0.08 \mathrm{~mm}$ to $2 \mathrm{~mm}$. The specific ratio is shown in Table 4 , and the grain-size distribution curves of three kinds of sample are shown in Figure 6.

3.2. Filter Paper Method. In the measurement of suction of unsaturated soils, compared with the pressure plate method or other methods, the filter paper method is more timeconsuming and cost-saving, and it also has larger measuring range [60]. Therefore, this paper uses the filter paper method to obtain the entire suction-saturation datasets of sand, silt, and clay.

This method was first proposed by Gardner [61], and since then, many researchers have been conducting further research. Feuerharmel et al. [62] and Agus and Schanz [63] compared and analyzed the filter paper method and other methods and found out that the value obtained by the filter paper method has higher accuracy. Marinho and Oliveira [64] also made a deeper discussion on the operation procedures and control conditions of the filter paper method.

In filter paper experiment, the most important procedure is to determine the calibration curve. Fawcett and Collis [65], Leong and Rahardjo [56], and other scholars, respectively, used the solution method or pressure plate instrument and other methods to calibrate the Whatman No. 42 filter paper calibration curve and the applicable range. The specific calibration equation is given. Scholars in China such as Tang et al. [66], Bai et al. [67], and Wang et al. [68] have measured the calibration curves of domestic doubleloop filter papers. The ASTM (American Society for Testing and Materials) has formulated the relevant test equipment and operating procedures of the filter paper method into a relevant standard-ASTM D5298-10, which also specifies the calibration curve of Whatman No. 42 filter paper. This paper used the calibration curve equation (equations (18) and (19)) 


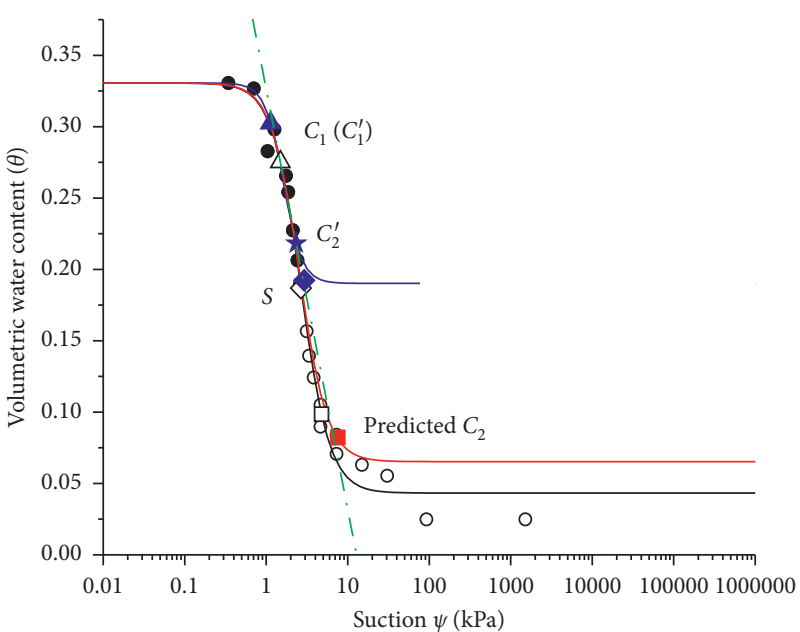

- Complete experimental data

- Limited experimental data

- SWCC fitting with complete data

- SWCC fitting with limited data

- SWCC fitting with limited data and predicted $C_{2}$

$\diamond S$ on the SWCC fitting with complete data

- $S$ on the SWCC fitting limited data

$\triangle C_{1}$ on the SWCC fitting with complete data

- $C_{1}$ on the SWCC fitting with limited data

$\square \quad C_{2}$ on the SWCC fitting with complete data

- Predicted $C_{2}$

$\star C_{2}{ }^{\prime}$

Figure 4: Example of the procedures and result of this method (data of sand sample from [46]).

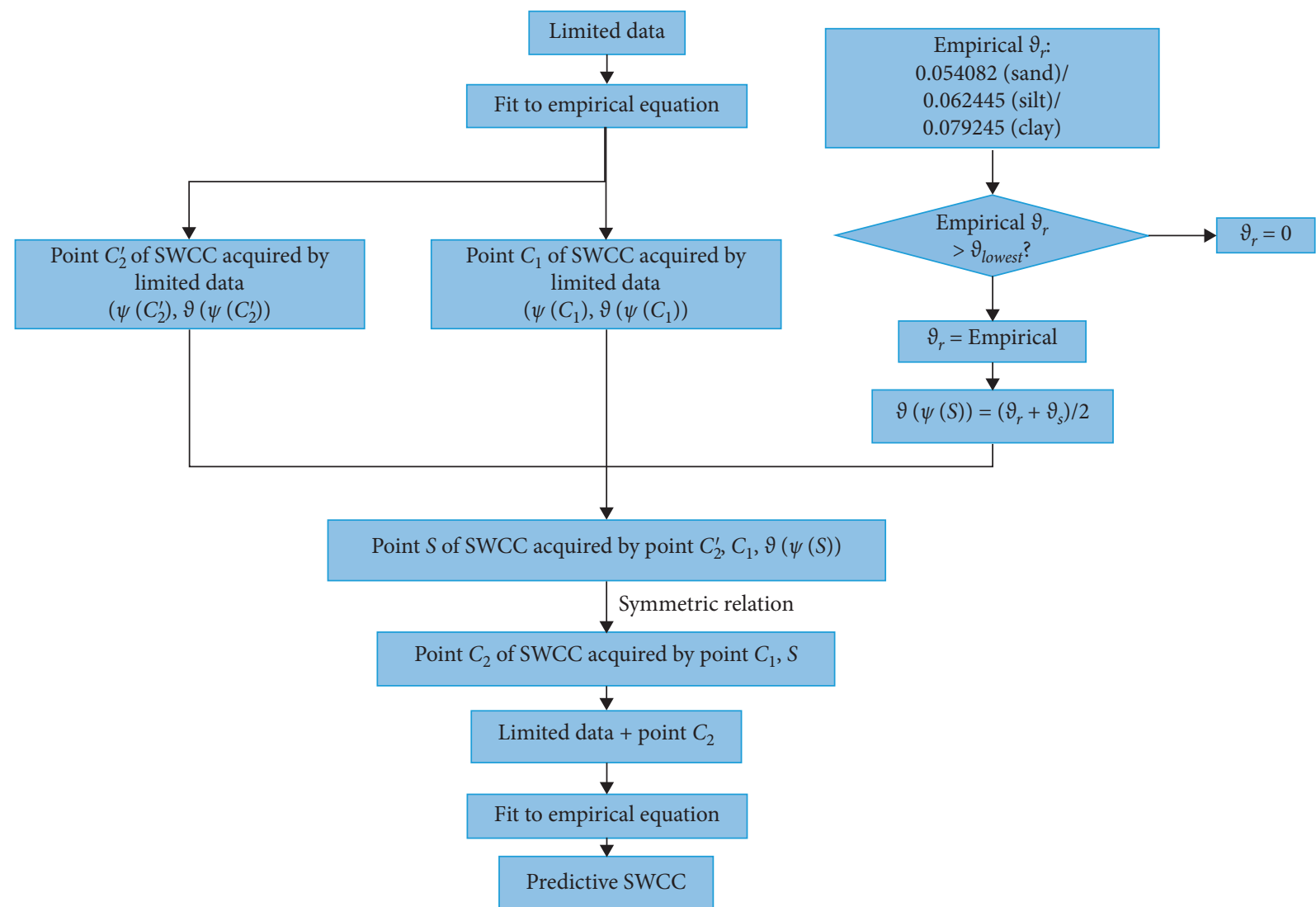

Figure 5: Procedures of the new method to predict SWCC based on the limited datasets. 
TABLE 4: Specific ratio of kaolin and sand in different types of soil.

\begin{tabular}{|c|c|c|c|c|c|}
\hline \multirow{2}{*}{ Type } & \multirow{2}{*}{ Specific gravity of soil solids } & \multirow{2}{*}{ Dry density } & \multicolumn{3}{|c|}{ Ingredients } \\
\hline & & & Sand (\%) & Silt (\%) & Clay (\%) \\
\hline Sand sample & 2.63 & 1.65 & 77 & 15 & 8 \\
\hline Silt sample & 2.66 & 1.30 & 40 & 50 & 10 \\
\hline Clay sample & 2.69 & 1.20 & 23 & 20 & 57 \\
\hline
\end{tabular}

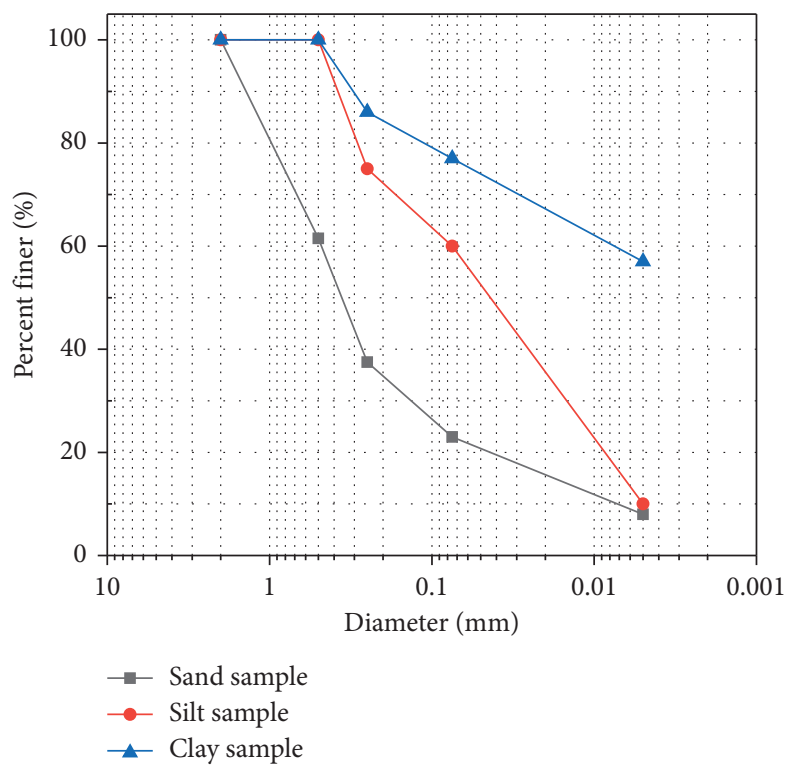

FIgURE 6: Grain-size distribution curves of sand, silt, and clay.

put forward by Leong to calculate suction, where $m_{a}$ is the mass of wet filter paper; $m_{b}$ is the mass of dry filter paper; and $w_{f}$ is the water content of processed filter paper:

$$
\begin{gathered}
w_{f}=\frac{m_{a}-m_{b}}{m_{b}}, \\
\left\{\begin{array}{l}
\log \psi=2.909-0.0229 w_{f}\left(w_{f} \geq 47\right), \\
\log \psi=4.945-0.0673 w_{f}\left(w_{f}<47\right) .
\end{array}\right.
\end{gathered}
$$

In addition, considering the hysteresis characteristics of SWCC, Houston et al. [69] and Leong et al. [70] have demonstrated through a large number of experiments that there is no significant difference in matrix suction during the hygroscopic process and dehumidifying process through a large number of experiments. Muñoz et al. [71] proposed that using wet filter paper can eliminate the hysteresis characteristic of SWCC, but the test results show that the results obtained with dry filter paper and wet filter paper are not much different. In summary, this paper uses the dry Whatman No. 42 filter to measure the suction of soil samples under different water content. The sketch of the ring-knife layout and the photos of experimental process are shown in Figure 7. And the results are shown in Table 5.

\section{Results and Discussion}

4.1. Verification Using the Experimental Results of Filter Paper Experiments. The datasets acquired by filter paper experiment covered entire suction range; thus, the curves they formed could be considered as the actual SWCC. Firstly, a part of the data of filter paper experiment were selected in order to make the curve they formed did not have two points of extreme value of curvature. Therefore, this processed dataset could be regarded as limited experimental data. The proposed method was applied to these limited data and compared quantitatively performance of this method applied to the experimental data by equations (13) and (20). In equation (20), $\varphi$ is the index parameter that quantifies improvement degree of the proposed method; $\eta_{1}$ is the deviation between the curve obtained by directly fitting limited experimental datasets to empirical equation and actual SWCC; and $\eta_{2}$ is the deviation between the curve obtained by the proposed method and the actual SWCC. The larger value $\varphi$ is, the greater the improvement the method makes. The specific comparison charts and calculation results charts are shown in Figure 8 and Table 6.

$$
\varphi=\frac{\eta_{1}-\eta_{2}}{\eta_{1}} .
$$




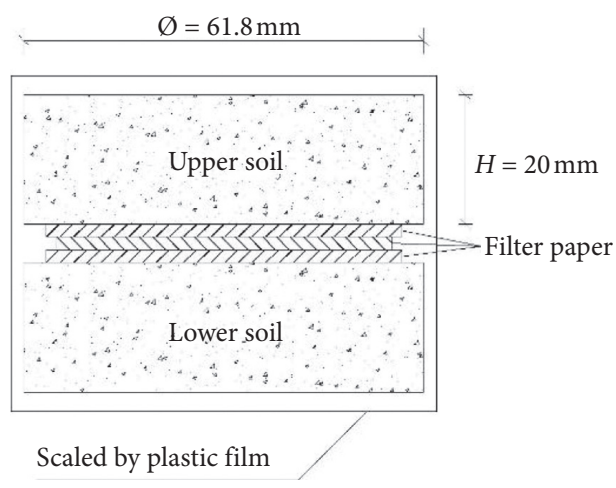

(a)

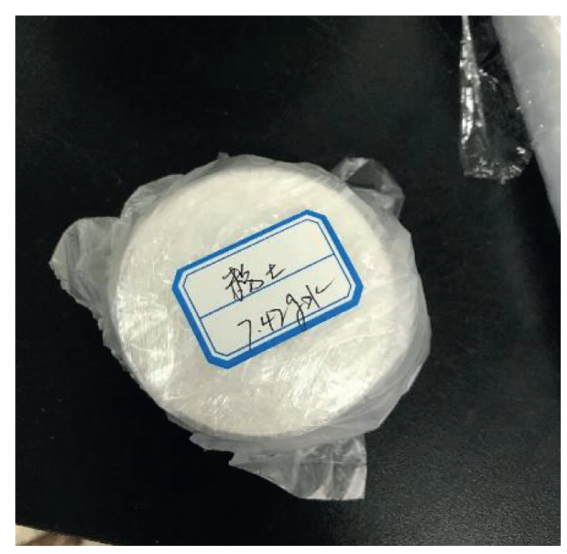

(c)

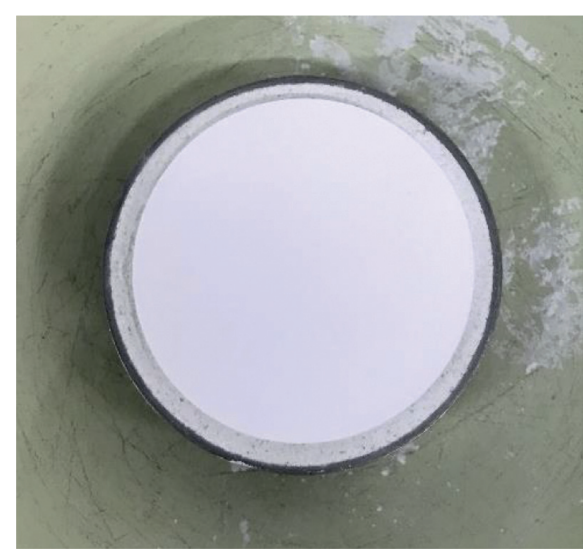

(b)

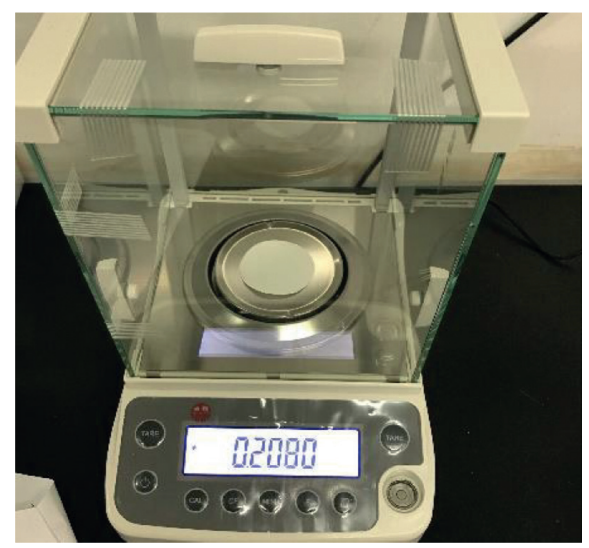

(d)

Figure 7: The sketch of the ring-knife layout and the photos of experimental process. (a) The sketch of ring-knife layout. (b) The Whatman No. 42 filter. (c) The wrapped ring-knife samples under different water content. (d) The precision balance measuring the filter paper.

TABLE 5: Results of the filter paper method.

\begin{tabular}{|c|c|c|c|c|c|c|c|c|}
\hline \multicolumn{3}{|c|}{ Sand } & \multicolumn{3}{|c|}{ Silt } & \multicolumn{3}{|c|}{ Clay } \\
\hline $\begin{array}{l}\text { Water content } \\
\text { of filter paper } \\
(\%)\end{array}$ & $\begin{array}{c}\text { Water content } \\
\text { of soil }(\%)\end{array}$ & $\begin{array}{c}\text { Suction } \\
(\mathrm{kPa})\end{array}$ & $\begin{array}{l}\text { Water content of } \\
\text { filter paper }(\%)\end{array}$ & $\begin{array}{c}\text { Water content } \\
\text { of soil }(\%)\end{array}$ & $\begin{array}{l}\text { Suction } \\
(\mathrm{kPa})\end{array}$ & $\begin{array}{l}\text { Water content of } \\
\text { filter paper }(\%)\end{array}$ & $\begin{array}{c}\text { Water content } \\
\text { of soil (\%) }\end{array}$ & $\begin{array}{l}\text { Suction } \\
(\mathrm{kPa})\end{array}$ \\
\hline 11.851 & 0.005 & 14042.388 & 23.917 & 0.014 & 2164.499 & 8.869 & 0.005 & 22288.953 \\
\hline 23.674 & 0.009 & 2247.753 & 24.988 & 0.014 & 1833.610 & 12.623 & 0.009 & 12458.153 \\
\hline 28.523 & 0.018 & 1060.181 & 28.558 & 0.030 & 1054.535 & 24.301 & 0.021 & 2039.631 \\
\hline 38.268 & 0.035 & 234.182 & 35.968 & 0.058 & 334.448 & 30.290 & 0.043 & 806.218 \\
\hline 46.567 & 0.052 & 64.722 & 41.279 & 0.089 & 146.865 & 35.422 & 0.085 & 363.979 \\
\hline 58.214 & 0.070 & 37.661 & 46.860 & 0.118 & 61.851 & 40.870 & 0.128 & 156.466 \\
\hline 74.665 & 0.088 & 15.818 & 52.807 & 0.147 & 50.087 & 48.520 & 0.172 & 62.789 \\
\hline 87.594 & 0.106 & 8.000 & 58.404 & 0.177 & 37.287 & 55.947 & 0.215 & 42.443 \\
\hline 101.226 & 0.115 & 3.899 & 66.698 & 0.206 & 24.078 & 63.047 & 0.258 & 29.190 \\
\hline 116.186 & 0.128 & 1.771 & 74.722 & 0.239 & 15.771 & 72.785 & 0.300 & 17.467 \\
\hline 126.357 & 0.142 & 1.036 & 75.993 & 0.254 & 14.749 & 76.154 & 0.322 & 14.624 \\
\hline 142.341 & 0.150 & 0.446 & 86.114 & 0.269 & 8.650 & 99.900 & 0.343 & 4.181 \\
\hline 155.374 & 0.160 & 0.224 & 135.265 & 0.280 & 0.648 & 187.996 & 0.427 & 0.040 \\
\hline & & & 145.300 & 0.295 & 0.382 & & & \\
\hline
\end{tabular}

From Table 6 and Figure 7, it is found out that the improvement this method made on three empirical equations ranges from 0.948 to 0.459 ; in other words, the curves gained from the method are much closer to the actual SWCC than the curves obtained by directly fitting limited data to empirical equations. Thus, this method performs well when 

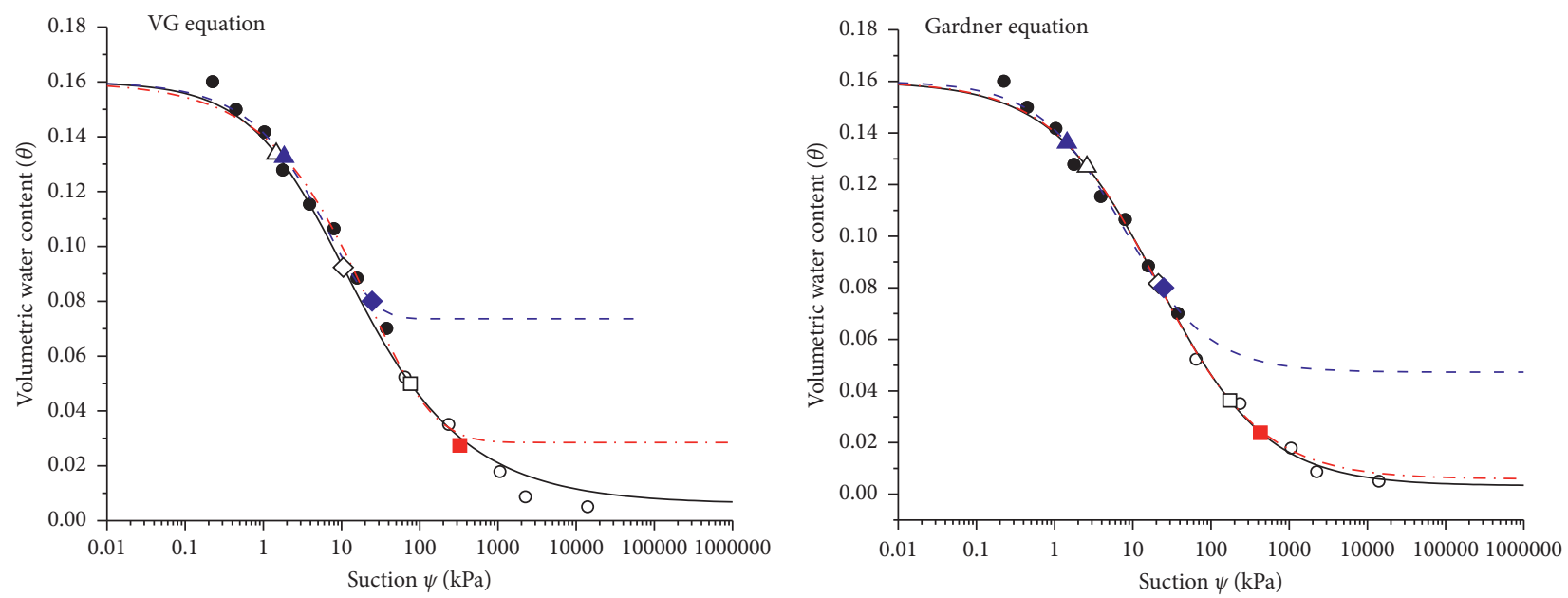

- Complete experimental data

- Limited experimental data

- SWCC fitting with complete data

- - - SWCC fitting with limited data

- - SWCC fitting with limited data and predicted $C_{2}$

$\diamond S$ on the SWCC fitting with complete data

- $S$ on the SWCC fitting limited data

$\triangle C_{1}$ on the SWCC fitting with complete data

- $C_{1}$ on the SWCC fitting with limited data

$\square \quad C_{2}$ on the SWCC fitting with complete data

- Predicted $C_{2}$

(a)
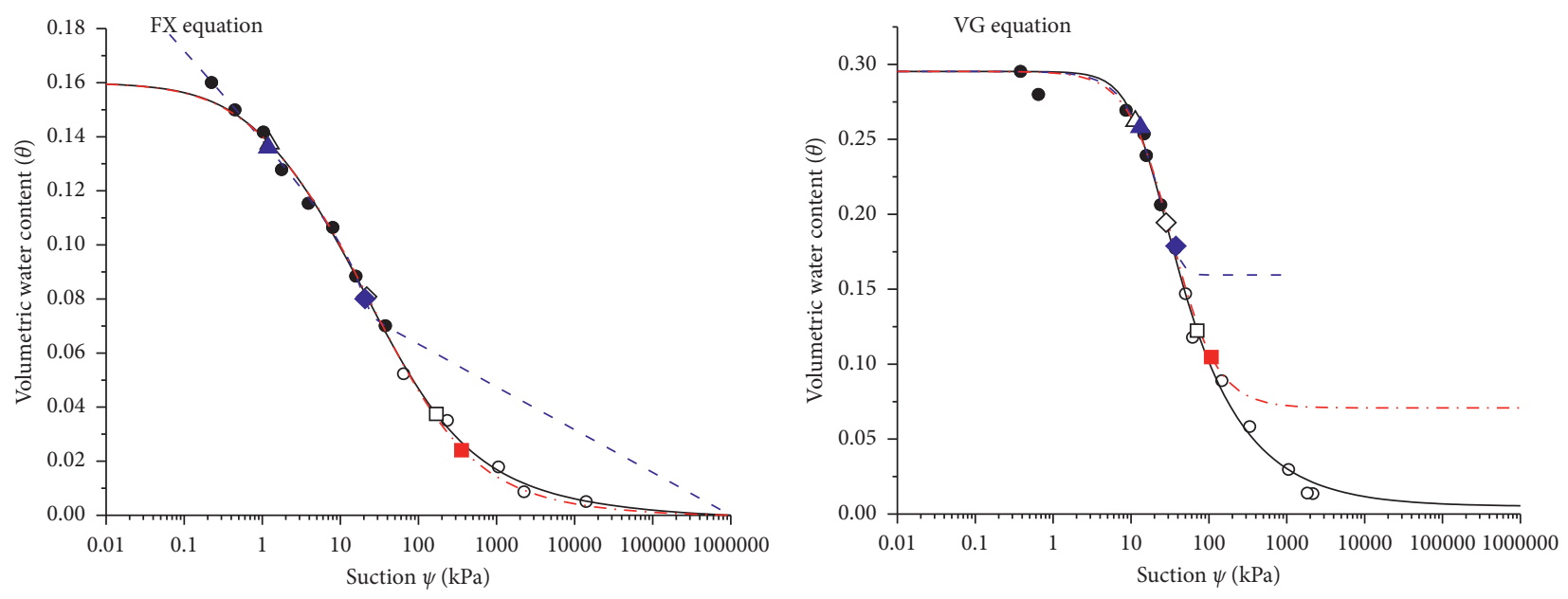

○ Complete experimental data

- Limited experimental data

- SWCC fitting with complete data

- - - SWCC fitting with limited data

-.. - SWCC fitting with limited data and predicted $C_{2}$

$\diamond S$ on the SWCC fitting with complete data

- $S$ on the SWCC fitting limited data

$\triangle C_{1}$ on the SWCC fitting with complete data

- $C_{1}$ on the SWCC fitting with limited data

$\square \quad C_{2}$ on the SWCC fitting with complete data

- Predicted $C_{2}$

- Complete experimental data

- Limited experimental data

- SWCC fitting with complete data

- - - SWCC fitting with limited data

-. - SWCC fitting with limited data and predicted $C_{2}$

$\diamond S$ on the SWCC fitting with complete data

- $S$ on the SWCC fitting limited data

$\triangle C_{1}$ on the SWCC fitting with complete data

- $C_{1}$ on the SWCC fitting with limited data

$\square \quad C_{2}$ on the SWCC fitting with complete data

- Predicted $C_{2}$

(b)

- Complete experimental data

- Limited experimental data

- SWCC fitting with complete data

- - - SWCC fitting with limited data

-. - SWCC fitting with limited data and predicted $C_{2}$

$\diamond S$ on the SWCC fitting with complete data

- $S$ on the SWCC fitting limited data

$\triangle C_{1}$ on the SWCC fitting with complete data

- $C_{1}$ on the SWCC fitting with limited data

$\square \quad C_{2}$ on the SWCC fitting with complete data

- Predicted $C_{2}$

(c)

(d)

Figure 8: Continued. 

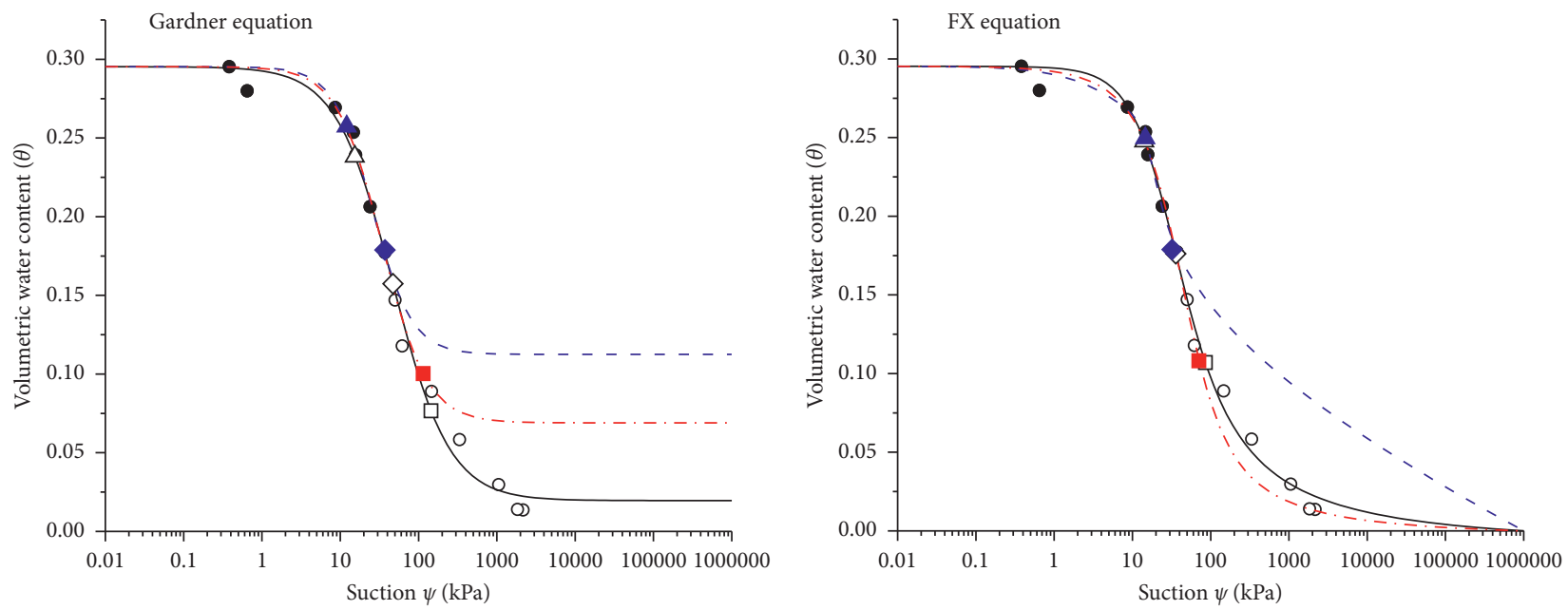

- Complete experimental data

- Limited experimental data

— SWCC fitting with complete data

- - - SWCC fitting with limited data

-. - SWCC fitting with limited data and predicted $C_{2}$

$\diamond S$ on the SWCC fitting with complete data

$\checkmark S$ on the SWCC fitting limited data

$\triangle C_{1}$ on the SWCC fitting with complete data

- $C_{1}$ on the SWCC fitting with limited data

$\square \quad C_{2}$ on the SWCC fitting with complete data

- Predicted $C_{2}$

(e)
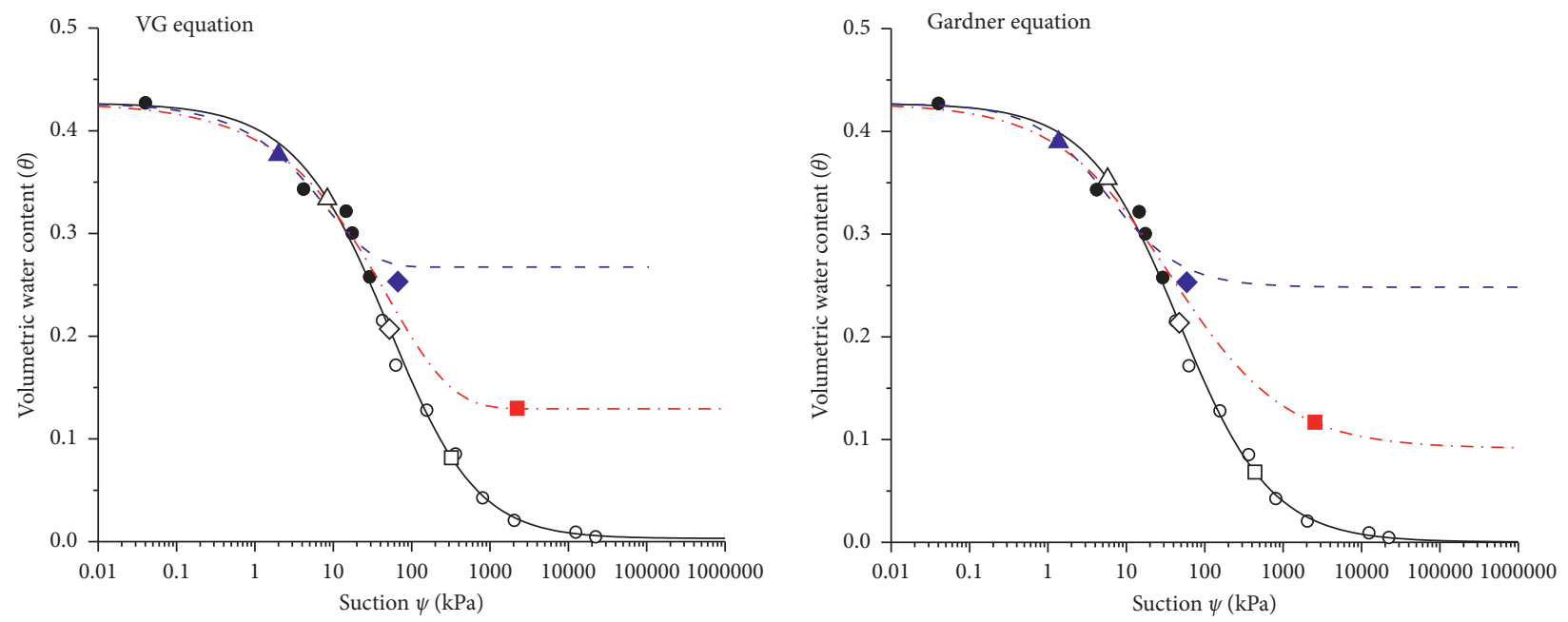

- Complete experimental data

- Limited experimental data

SWCC fitting with complete data

- - - SWCC fitting with limited data

-. - SWCC fitting with limited data and predicted $C_{2}$

$\diamond S$ on the SWCC fitting with complete data

- $S$ on the SWCC fitting limited data

$\triangle C_{1}$ on the SWCC fitting with complete data

$\Delta C_{1}$ on the SWCC fitting with limited data

$\square \quad C_{2}$ on the SWCC fitting with complete data

- Predicted $C_{2}$

O Complete experimental data

- Limited experimental data

- SWCC fitting with complete data

- - - SWCC fitting with limited data

-.. SWCC fitting with limited data and predicted $C_{2}$

$\diamond S$ on the SWCC fitting with complete data

- $S$ on the SWCC fitting limited data

$\triangle C_{1}$ on the SWCC fitting with complete data

- $C_{1}$ on the SWCC fitting with limited data

$\square \quad C_{2}$ on the SWCC fitting with complete data

- Predicted $C_{2}$

(f)

○ Complete experimental data

- Limited experimental data

— SWCC fitting with complete data

- - - SWCC fitting with limited data

-. - SWCC fitting with limited data and predicted $C_{2}$

$\diamond S$ on the SWCC fitting with complete data

- $S$ on the SWCC fitting limited data

$\triangle C_{1}$ on the SWCC fitting with complete data

A $C_{1}$ on the SWCC fitting with limited data

$\square \quad C_{2}$ on the SWCC fitting with complete data

- Predicted $C_{2}$

(g)

Figure 8: Continued. 


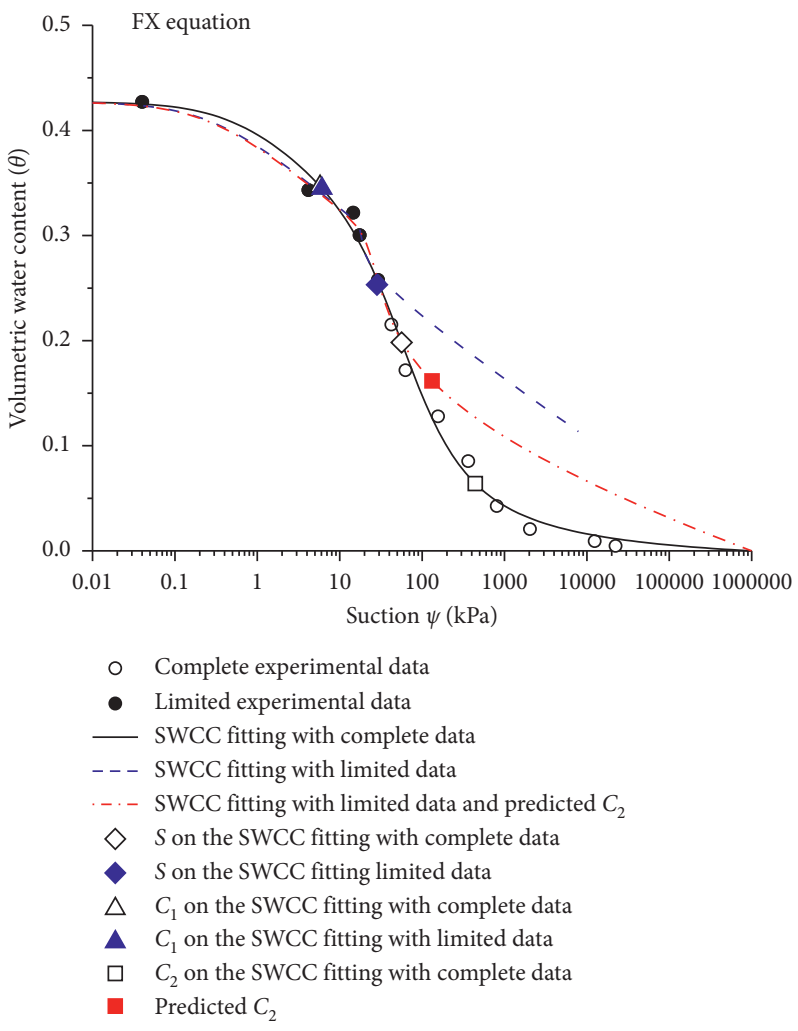

(i)

FiguRE 8: The results of applying the method to data of filter paper experiment (sand, silt, and clay): (a-c) sand (data from filter paper method); (d-f) silt (data from filter paper method); (g-i) clay (data from filter paper method).

TABLE 6: Calculation of effectiveness of the prediction method.

\begin{tabular}{lccccccccc}
\hline \multirow{2}{*}{ Data resource } & \multicolumn{3}{c}{ VG equation } & \multicolumn{3}{c}{ Gardner equation } & \multicolumn{3}{c}{ FX equation } \\
& $\eta_{1}$ & $\eta_{2}$ & $\varphi$ & $\eta_{1}$ & $\eta_{2}$ & $\varphi$ & $\eta_{1}$ & $\eta_{2}$ & $\varphi$ \\
\hline Sand (filter paper) & 0.247 & 0.066 & 0.735 & 0.158 & 0.008 & 0.948 & 0.124 & 0.007 \\
Silt (filer paper) & 0.561 & 0.210 & 0.626 & 0.355 & 0.183 & 0.484 & 0.187 & 0.037 & 0.943 \\
Clay (filter paper) & 1.012 & 0.468 & 0.538 & 0.942 & 0.407 & 0.568 & 0.354 & 0.192 & 0.459 \\
Sand [46] & 0.758 & 0.308 & 0.593 & 0.790 & 0.146 & 0.815 & 0.129 & 0.117 & 0.097 \\
Silt [47] & 0.639 & 0.124 & 0.806 & 0.444 & 0.297 & 0.331 & 0.015 & 0.189 & -11.694 \\
Clay [51] & 0.720 & 0.172 & 0.761 & 0.612 & 0.168 & 0.725 & 0.334 & 0.157 & 0.529 \\
\hline
\end{tabular}

it is applied to the data from filter paper experiments on three different types of soils. However, the performance of this method on these three datasets is not stable, namely, it does not show any preference of applicability to types of soil. In the perspective of empirical equations, the value of $\eta_{1}$ and $\eta_{2}$ of FX equation is lower than that of VG equation and Gardner equation, which means the curves obtained by FX equation were closer to the actual SWCC. That is because the FX equation has a restriction point $(1,000,000,0)$ and the deviation resulting from directly fitting FX equations to limited data relatively decreases. When this method is used on FX equation, there two points are added to the limited data, besides point $C_{2}$, so that the final obtained curve is closer to actual SWCC.
4.2. Verification Using the Previous Experimental Data. Considering the limitedness and occasionality of only three experimental datasets, this paper selected and collected the entire previous experimental data according to the standard mentioned above to verify the effectiveness of the proposed method. Similarly, the entire data were selected as above processes, and in the dataset of silt and clay, the points whose suction were lower than $2,000 \mathrm{kPa}$ and were selected in order to simulate limitation of the measurement range. The calculation results and comparison charts are shown in Table 6 and Figure 9.

Comparing with the performance of this method on filter paper experimental data, its application of silt on FX equation was not well. Generally, some improvement of this 

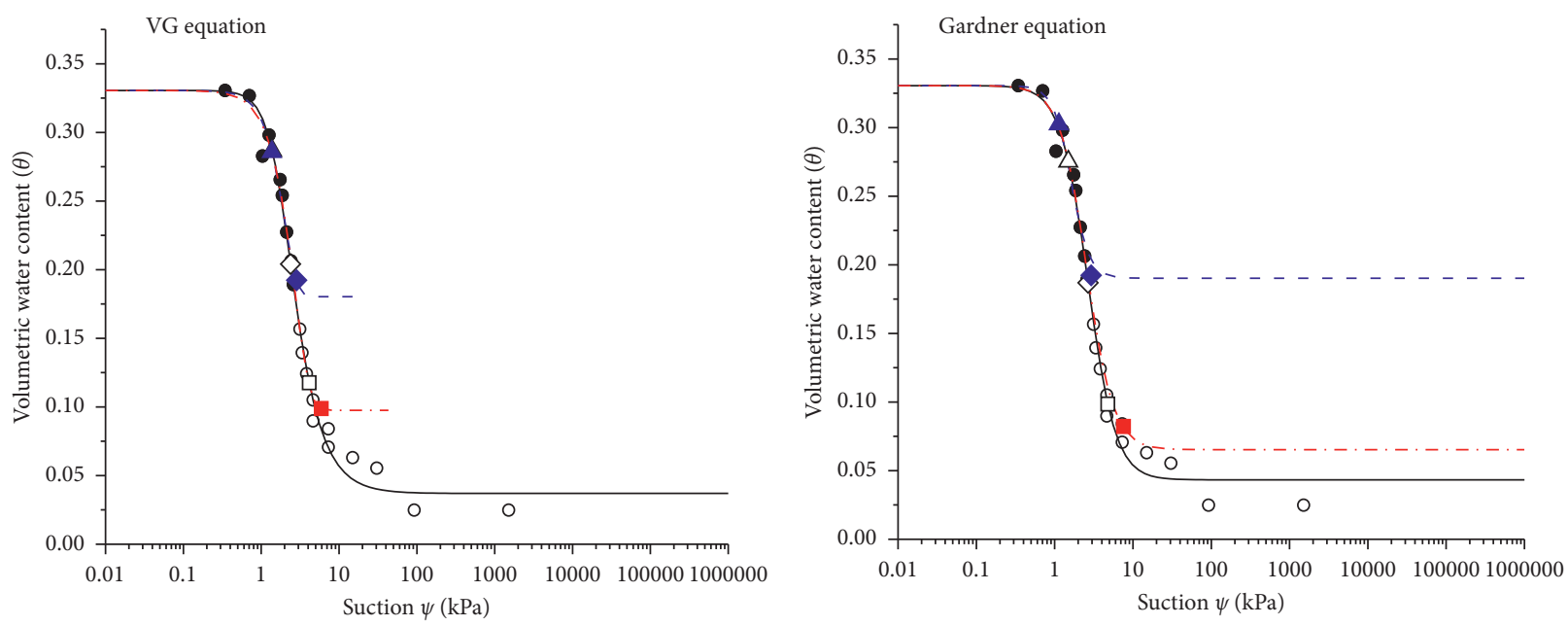

- Complete experimental data

- Limited experimental data

- SWCC fitting with complete data

- - - SWCC fitting with limited data

-. SWCC fitting with limited data and predicted $C_{2}$

$\diamond S$ on the SWCC fitting with complete data

$\checkmark S$ on the SWCC fitting limited data

$\triangle C_{1}$ on the SWCC fitting with complete data

- $C_{1}$ on the SWCC fitting with limited data

$\square \quad C_{2}$ on the SWCC fitting with complete data

- Predicted $C_{2}$

(a)

- Complete experimental data

- Limited experimental data SWCC fitting with complete data

- - - SWCC fitting with limited data

... SWCC fitting with limited data and predicted $C_{2}$

$\diamond S$ on the SWCC fitting with complete data

- $S$ on the SWCC fitting limited data

$\triangle C_{1}$ on the SWCC fitting with complete data

$\Delta C_{1}$ on the SWCC fitting with limited data

- $C_{2}$ on the SWCC fitting with complete data

- Predicted $C_{2}$

(b)
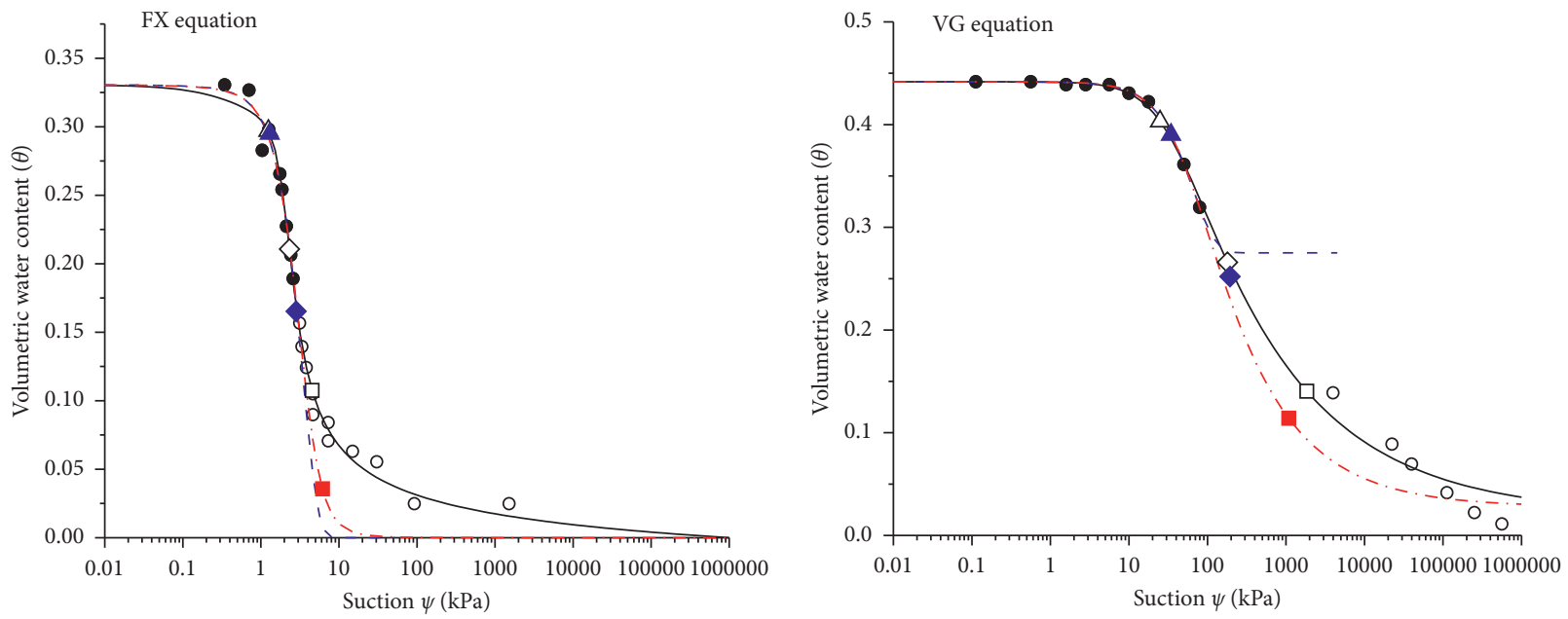

- Complete experimental data

- Limited experimental data

- SWCC fitting with complete data

- - - SWCC fitting with limited data

- - SWCC fitting with limited data and predicted $C_{2}$

$\diamond \quad S$ on the SWCC fitting with complete data

$\checkmark S$ on the SWCC fitting limited data

$\triangle C_{1}$ on the SWCC fitting with complete data

$\Delta C_{1}$ on the SWCC fitting with limited data

$\square \quad C_{2}$ on the SWCC fitting with complete data

- Predicted $C_{2}$

- Complete experimental data

- Limited experimental data SWCC fitting with complete data

- - - SWCC fitting with limited data

-. - SWCC fitting with limited data and predicted $C_{2}$

$\diamond S$ on the SWCC fitting with complete data

$\checkmark S$ on the SWCC fitting limited data

$\triangle C_{1}$ on the SWCC fitting with complete data

$\Delta C_{1}$ on the SWCC fitting with limited data

$\square \quad C_{2}$ on the SWCC fitting with complete data

- Predicted $C_{2}$

(c)

(d)

Figure 9: Continued. 

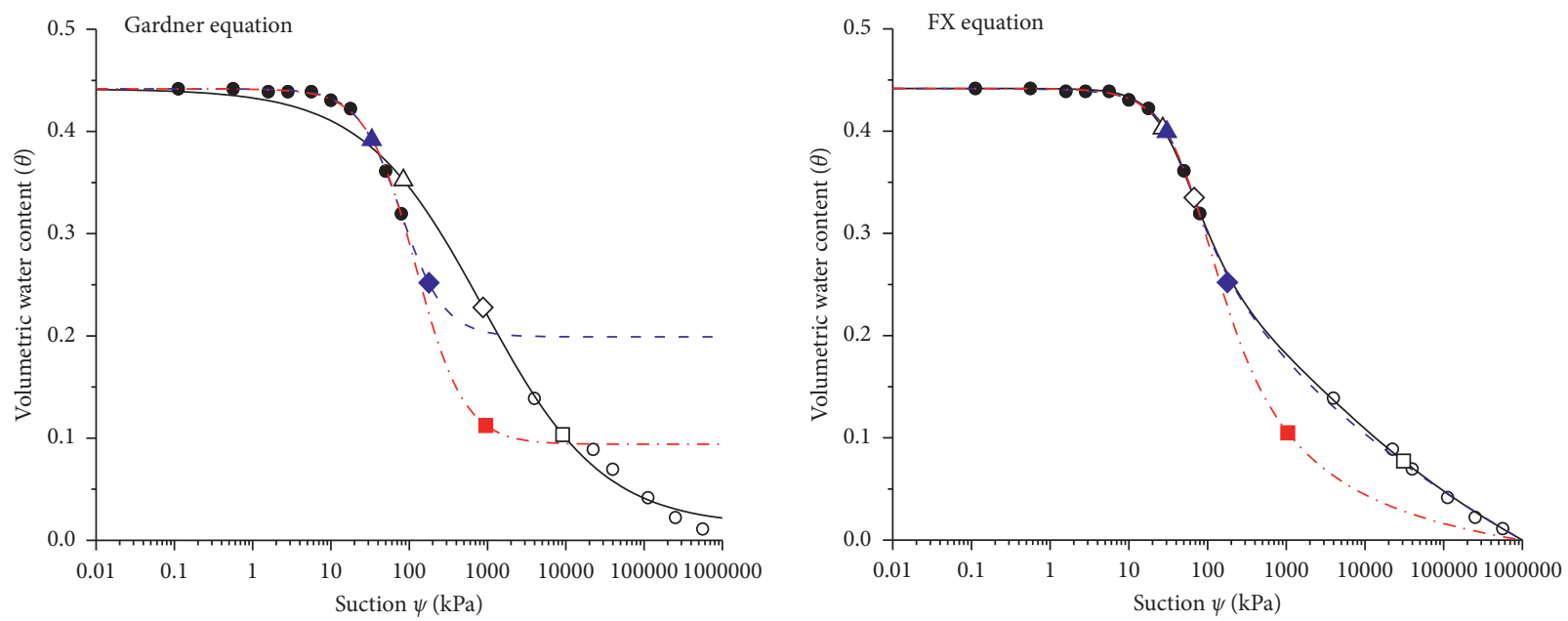

- Complete experimental data

- Limited experimental data

- SWCC fitting with complete data

- - - SWCC fitting with limited data

-.. SWCC fitting with limited data and predicted $C_{2}$

$\diamond S$ on the SWCC fitting with complete data

$-S$ on the SWCC fitting limited data

$\triangle C_{1}$ on the SWCC fitting with complete data

- $C_{1}$ on the SWCC fitting with limited data

$\square \quad C_{2}$ on the SWCC fitting with complete data

- Predicted $C_{2}$

(e)
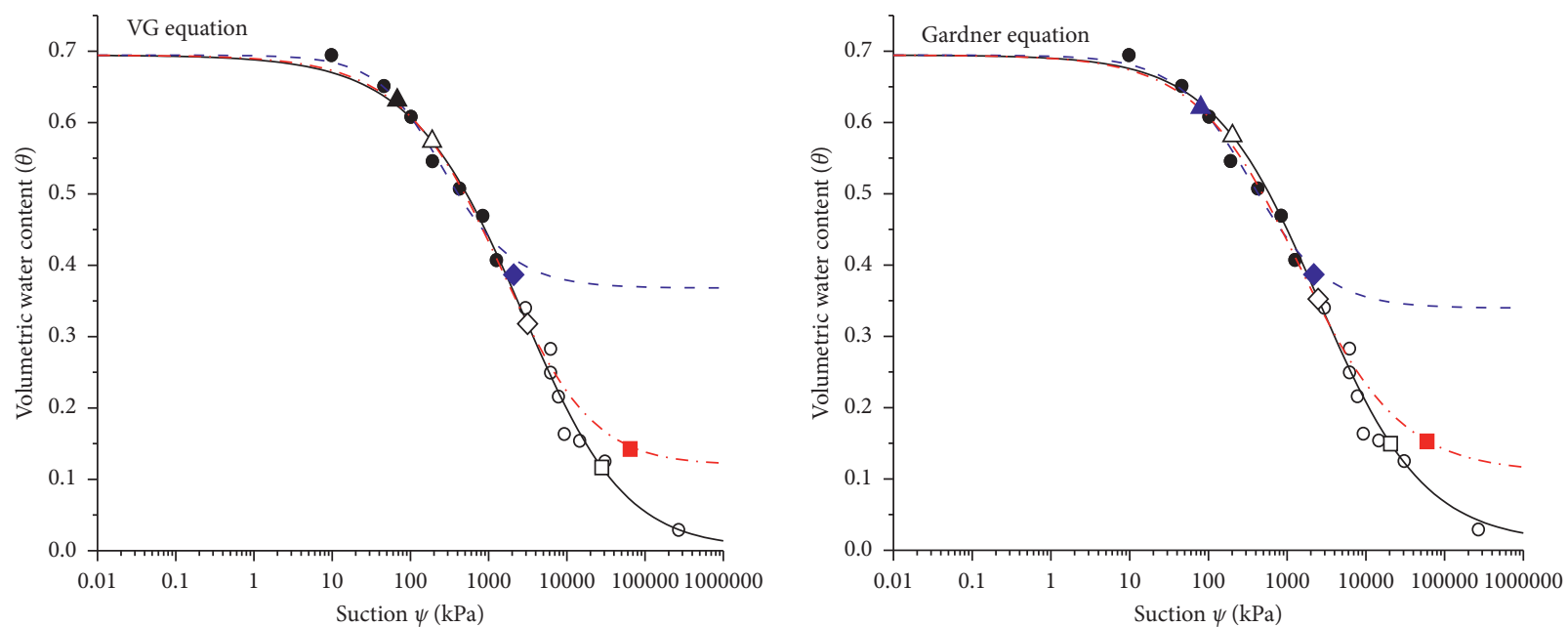

- Complete experimental data

- Limited experimental data

- SWCC fitting with complete data

- _ - SWCC fitting with limited data

. . - SWCC fitting with limited data and predicted $C_{2}$

$\diamond S$ on the SWCC fitting with complete data

$\checkmark S$ on the SWCC fitting limited data

$\triangle C_{1}$ on the SWCC fitting with complete data

$\Delta C_{1}$ on the SWCC fitting with limited data

$C_{2}$ on the SWCC fitting with complete data

- Predicted $C_{2}$

- Complete experimental data

- Limited experimental data SWCC fitting with complete data

- - - SWCC fitting with limited data

- . - SWCC fitting with limited data and predicted $C_{2}$

$\diamond S$ on the SWCC fitting with complete data

- $S$ on the SWCC fitting limited data

$\triangle C_{1}$ on the SWCC fitting with complete data

- $C_{1}$ on the SWCC fitting with limited data

$\square \quad C_{2}$ on the SWCC fitting with complete data

- Predicted $C_{2}$

(f)

- Complete experimental data

- Limited experimental data

— SWCC fitting with complete data

- - - SWCC fitting with limited data

. - - SWCC fitting with limited data and predicted $C_{2}$

$\diamond S$ on the SWCC fitting with complete data

- $S$ on the SWCC fitting limited data

$\triangle C_{1}$ on the SWCC fitting with complete data

A $C_{1}$ on the SWCC fitting with limited data

$\square \quad C_{2}$ on the SWCC fitting with complete data

- Predicted $C_{2}$

Figure 9: Continued. 


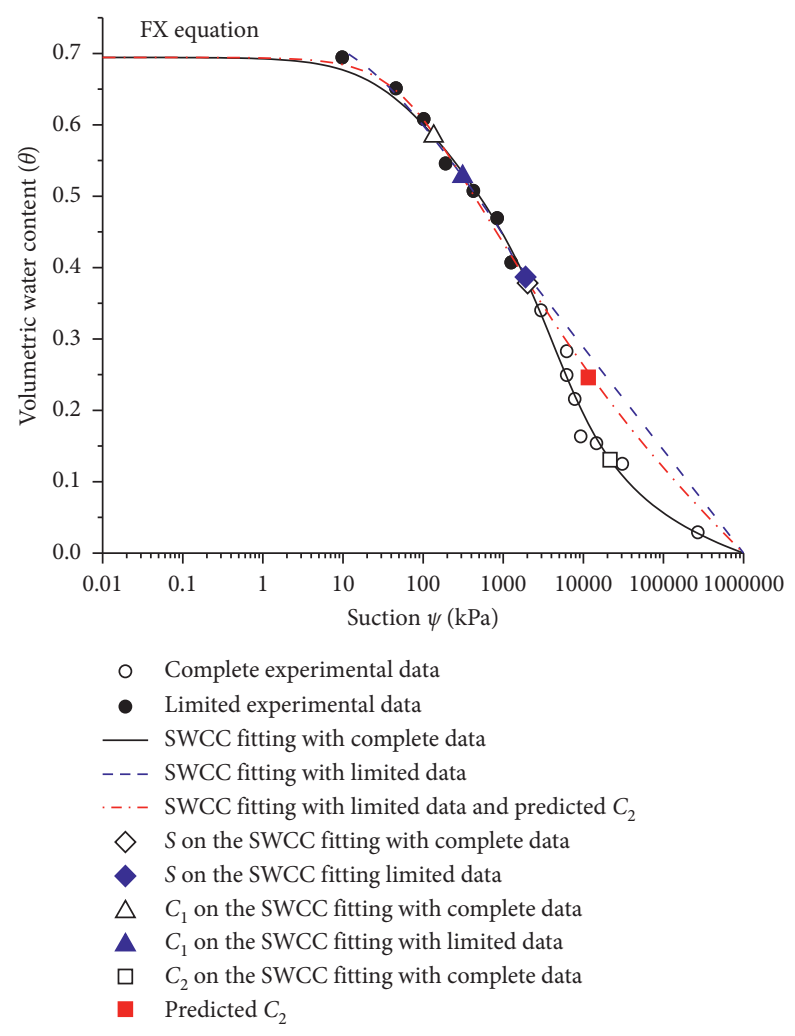

(i)

FIgURE 9: The results of applying the method to previous experimental data of sand, silt, and clay samples: (a-c) sand (data from [46]); (d-f) 9silt (data from [47]); (g-i) clay (data from [51]).

method has been made at different degree ranging from 0.815 to 0.097 , expect the result of silt on FX equation. However, the value of $\eta_{1}$ and $\eta_{2}$ under FX equation was also lower than that under VG equation and Gardner equation. From Figure 10, the performance of this method did not greatly vary with soil types, and the averaged improvement was the largest on $\mathrm{VG}$ equation among three empirical equations.

4.3. Discussion. Overall, the data processed by this method could acquire more accurate SWCC to some extent, comparing with the limited data. From a series of calculation, it is found that the values of $\eta_{1}$ and $\eta_{2}$ under FX equation are lower than those under VG equation and Gardner equation. That is because the restriction point $(1,000,000,0)$ makes the fitting results of FX equation more approximate than those of other empirical equations. For sake of this, the improvement of adding point $C_{2}$ on $\mathrm{FX}$ equation is not stable. Among three empirical equations, the averaged improvement of this method is the largest on VG equation. Therefore, it is suggested this method would achieve the better effectiveness when it is combined with VG equation.

In addition, this study was focussed on the prediction about typical unimodal SWCC. The empirical equations this method based on and discussed in this paper were not applicable to both unimodal SWCC and bimodal SWCC. Therefore, the proposed method is not suitable for the prediction of bimodal

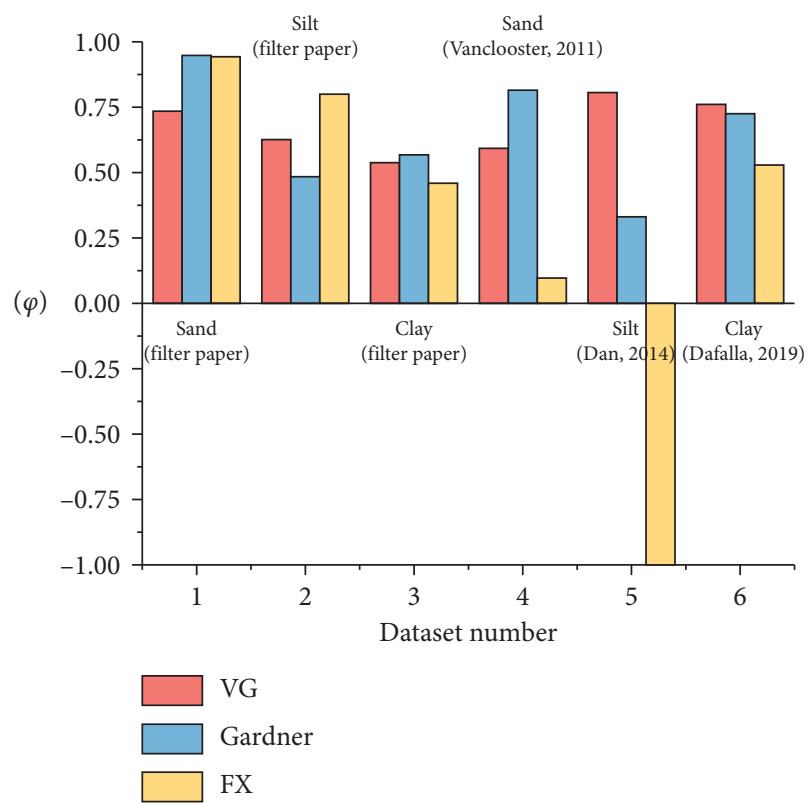

Figure 10: The improvements of this method on different soil types and different empirical equations (VG equation, Gardner equation, and FX equation).

SWCC. SWCCs of residual and colluvial soils commonly show bimodal behavior; thus, the applicability of the proposed method on those soils is limited. 
What this method needs to be improved in the future is how to make the value of $\theta\left(\psi_{S}\right)$ or residual water content $\theta_{r}$ closer to reality because the value of $\theta_{r}$ is the averaged statistics of a quantity of entire datasets in this paper, other than some regularity of the soil characteristics. According to the analysis about the physical meaning of three points $S$, $C_{1}$, and $C_{2}$ and the regularity presented by calculation above, the value of $\theta_{r}$ may have some qualitative relations with soil properties (mineral composition, pore structure, and dense state). Thus, the future work can be focused on finding some specific relation between some soil index and the value of residual water content $\theta_{r}$, aiming at obtaining more accurate $\theta_{r}$ whose physical meaning are also more specific.

\section{Conclusions}

This paper proposed a geometrical method based on a symmetric relation of three critical points (point $S$ which is the largest absolute value of slope; two points $C_{1}$ and $C_{2}$ which are two extreme points of curvature) on SWCC in semilogarithmic coordinate to preprocess limited data before directly fitting with conventional empirical equations. Meantime, a series of theoretical derivation and confirmation computation proved this symmetric relation of three critical points exhibited well in all three conventional empirical equations, especially in Gardner equation. The accuracy of SWCC obtained by empirical equations depends on the dataset whether the formed curve includes the critical shape characteristic point of maximum curvature (point $C_{2}$ ). If this point has not been reached in experimental data, even many numbers of points obtained, the fitting results directly by the empirical model could be large error. Three datasets of sand, silt, and clay acquired by the filter paper method were used to testify applicability of this method. The performance of this method did not greatly vary with soil types, but it was floating a lot on different empirical equations. Through quantitative analysis, the method generally performed well on sand, silt, and clay. In perspective of empirical equations, the evident improvement can be made when the proposed method is combined with VG equation, Gardner equation, and FX equation, but averaged improvement was the largest on the VG equation among three empirical equations. Generally, this method provides good evidence of wide application potential. And future work could be concentrated on finding out the relation between residual water content $\theta_{r}$ and soil characteristics instead of using averaged statistical value.

\section{Data Availability}

The data used to support the findings of this study are available from the corresponding author upon request.

\section{Conflicts of Interest}

The authors declare that there are no conflicts of interest regarding the publication of this paper.

\section{Acknowledgments}

The research work herein was supported by the National Natural Science Foundation of China (No. 41702299) and Foundation of State Key Laboratory of Frozen Soil Engineering (No. SKLFSE201916).

\section{References}

[1] X. G. Zhong, X. Zeng, and J. G. Rose, "Shear modulus and damping ratio of rubber-modified asphalt mixes and unsaturated subgrade soils," Journal of Materials in Civil Engineering, vol. 14, no. 6, pp. 496-502, 2002.

[2] Z. D. Sun, Z. X. Li, H. Q. Song et al., "Effect of soil-water characteristic curve on runoff in sponge city construction," China Water and Wastewater, vol. 36, no. 9, pp. 117-122, 2020.

[3] Y. Mualem and G. Dagan, "Hydraulic conductivity of soils: unified approach to the statistical models," Soil Science Society of America Journal, vol. 42, no. 3, pp. 392-395, 1978.

[4] B. Ghanbarian, V. Taslimitehrani, G. Dong, and Y. A. Pachepsky, "Sample dimensions effect on prediction of soil water retention curve and saturated hydraulic conductivity," Journal of Hydrology, vol. 528, pp. 127-137, 2015.

[5] D. G. Fredlund, N. R. Morgenstern, and R. A. Widger, "The shear strength of unsaturated soils," Canadian Geotechnical Journal, vol. 15, no. 3, pp. 313-321, 1978.

[6] P. C. Lim, S. L. Barbour, and D. G. Fredlund, "The influence of degree of saturation on the coefficient of aqueous diffusion," Canadian Geotechnical Journal, vol. 35, no. 5, pp. 811-827, 1998.

[7] R. Solone, M. Bittelli, F. Tomei, and F. Morari, "Errors in water retention curves determined with pressure plates: effects on the soil water balance," Journal of Hydrology, vol. 470-471, pp. 65-74, 2012.

[8] B. Gong, H. Wu, and B. Wang, "Influence of stress states on soil-water characteristics of expansive soils," Rock and Soil Mechanics, vol. 25, no. 12, pp. 1915-1918, 2004.

[9] S. S. Agus, E. C. Leong, and H. Rahardjo, "Soil-water characteristic curves of Singapore residual soils," Unsaturated Soil Concepts and Their Application in Geotechnical Practice, vol. 19, no. 3, pp. 285-309, 2001.

[10] P. K. Patrick, H. W. Olsen, and J. D. Higgins, "Comparison of chilled-mirror measurements and filter paper estimates of total soil suction," Geotechnical Testing Journal, vol. 30, no. 5, pp. 360-367, 2007.

[11] D. G. Fredlund, "Unsaturated soil mechanics in engineering practice," Journal of Geotechnical and Geoenvironmental Engineering, vol. 132, no. 3, pp. 286-321, 2006.

[12] J. H. M. Wösten, Y. A. Pachepsky, and W. J. Rawls, "Pedotransfer functions: bridging the gap between available basic soil data and missing soil hydraulic characteristics," Journal of Hydrology, vol. 251, no. 3-4, pp. 123-150, 2001.

[13] L. M. Arya and J. F. Paris, "A physicoempirical model to predict the soil moisture characteristic from particle-size distribution and bulk density data," Soil Science Society of America Journal, vol. 45, no. 6, pp. 1023-1030, 1981.

[14] S. Rafraf, L. Guellouz, H. Guiras, and R. Bouhlila, "A new model using dynamic contact angle to predict hysteretic soil water retention curve," Soil Science Society of America Journal, vol. 80, no. 6, pp. 1433-1442, 2016.

[15] S. W. Tyler and S. W. Wheatcraft, "Application of fractal mathematics to soil water retention estimation," Soil Science Society of America Journal, vol. 53, no. 4, pp. 987-996, 1989. 
[16] B. Ghanbarian-alavijeh, A. Liaghat, G.-H. Huang, and M. T. Van Genuchten, "Estimation of the van Genuchten soil water retention properties from soil textural data," Pedosphere, vol. 20, no. 4, pp. 456-465, 2010.

[17] M. T. van Genuchten, "A closed-form equation for predicting the hydraulic conductivity of unsaturated soils," Soil Science Society of America Journal, vol. 44, no. 5, pp. 892-898, 1980.

[18] Y. W. Zhang, Z. P. Song, X. L. Weng, and Y. L. Xie, "A new soil-water characteristic curve model for unsaturated loess based on wetting-induced pore deformation," Geofluids, vol. 2019, Article ID 1672418, 14 pages, 2019.

[19] G. L. Tao, Y. Y. Chen, H. L. Xiao, Y. Chen, and W. Peng, "Comparative analysis of soil-water characteristic curve in fractal and empirical models," Advances in Materials Science and Engineering, vol. 2020, Article ID 1970314, 10 pages, 2020.

[20] K. Pham, D. Kim, Y. Yoon, and H. Choi, "Analysis of neural network based pedotransfer function for predicting soil water characteristic curve," Geoderma, vol. 351, pp. 92-102, 2019.

[21] L. Wang, W. G. Zhang, and F. Y. Chen, "Bayesian approach for predicting soil-water characteristic curve from particlesize distribution data," Energies, vol. 12, no. 15, 2019.

[22] C. P. K. Gallage and T. Uchimura, "Effects of dry density and grain size distribution on soil-water characteristic curves of sandy soils," Soils and Foundations, vol. 50, no. 1, pp. 161-172, 2010.

[23] L. Zhang and Q. Chen, "Predicting bimodal soil-water characteristic curves," Journal of Geotechnical and Geoenvironmental Engineering, vol. 131, 2005.

[24] Q. Zhai, H. Rahardjo, and A. Satyanaga, "Estimation of air permeability function from soil-water characteristic curve," Canadian Geotechnical Journal, vol. 56, no. 4, pp. 505-513, 2019.

[25] Y. Perera, C. Zapata, W. Houston, and S. Houston, "Prediction of the soil-water characteristic curve based on grainsize-distribution and index properties," in Proceedings of the Geo-Frontiers Congress 2005, Austin, TX, USA, October 2005.

[26] D. G. Fredlund and A. Xing, "Equations for the soil-water characteristic curve," Canadian Geotechnical Journal, vol. 31, no. 4, pp. 521-532, 1994.

[27] N. Lu and Y. Dong, "Correlation between soil-shrinkage curve and water-retention characteristics," Journal of Geotechnical and Geoenvironmental Engineering, vol. 143, no. 9, 2017.

[28] B. Lin and A. B. Cerato, "Hysteretic soil water characteristics and cyclic swell-shrink paths of compacted expansive soils," Bulletin of Engineering Geology and the Environment, vol. 72, no. 1, pp. 61-70, 2013.

[29] Q. Zhai, H. Rahardjo, A. Satyanaga, G. Dai, and Y. Zhuang, "Framework to estimate the soil-water characteristic curve for soils with different void ratios," Bulletin of Engineering $\mathrm{Ge}$ ology and the Environment, vol. 79, no. 8, pp. 4399-4409, 2020.

[30] W. R. Gardner, "Some steady-state solutions of the unsaturated moisture flow equation with application to evaporation from a water table," Soil Science, vol. 85, no. 4, pp. 228-232, 1958.

[31] D. G. Fredlund, A. Xing, M. D. Fredlund, and S. L. Barbour, "The relationship of the unsaturated soil shear strength to the soil-water characteristic curve," Canadian Geotechnical Journal, vol. 33, no. 3, pp. 440-448, 1996.

[32] R. H. Brooks and A. T. Corey, "Hydraulic properties of porous media," Hydrology Paper, vol. 7, pp. 26-28, 1964.

[33] M. Wijaya and E. C. Leong, "Equation for unimodal and bimodal soil-water characteristic curves," Soils and Foundations, vol. 56, no. 2, pp. 291-300, 2016.
[34] M. Aubertin, J.-F. Ricard, and R. P. Chapuis, "A predictive model for the water retention curve: application to tailings from hard-rock mines," Canadian Geotechnical Journal, vol. 35, no. 1, pp. 55-69, 1998.

[35] W. S. Sillers and D. G. Fredlund, "Statistical assessment of soil-water characteristic curve models for geotechnical engineering," Canadian Geotechnical Journal, vol. 38, no. 6, pp. 1297-1313, 2001.

[36] L. Wang, Z.-J. Cao, D.-Q. Li, K.-K. Phoon, and S.-K. Au, "Determination of site-specific soil-water characteristic curve from a limited number of test data - a bayesian perspective," Geoscience Frontiers, vol. 9, no. 6, pp. 1665-1677, 2018.

[37] X. Ren, J. Kang, J. Ren, X. Chen, and M. Zhang, "A method for estimating soil water characteristic curve with limited experimental data," Geoderma, vol. 360, Article ID 114013, 2020.

[38] M. Aubertin, M. Mbonimpa, B. Bussière, and R. P. Chapuis, "A model to predict the water retention curve from basic geotechnical properties," Canadian Geotechnical Journal, vol. 40, no. 6, pp. 1104-1122, 2003.

[39] S. K. Vanapalli, D. G. Fredlund, D. E. Pufahl, and A. W. Clifton, "Model for the prediction of shear strength with respect to soil suction," Canadian Geotechnical Journal, vol. 33, no. 3, pp. 379-392, 1996.

[40] X. Zhang, "Research on the principle problem relating to soilwater characteristic curve and its application in unsaturated soil mechanics," Doctoral Dissertation, Beijng Jiaotong University, Beijing, China, 2010.

[41] S. Assouline, D. Tessier, and A. Bruand, "A conceptual model of the soil water retention curve," Water Resources Research, vol. 34, no. 2, pp. 223-231, 1998.

[42] X. Li, L. M. Zhang, and D. G. Fredlund, "Wetting front advancing column test for measuring unsaturated hydraulic conductivity," Canadian Geotechnical Journal, vol. 46, no. 12, pp. 1431-1445, 2009.

[43] C. M. P. Vaz, M. de Freitas Iossi, J. de Mendonça Naime et al., "Validation of the arya and paris water retention model for Brazilian soils," Soil Science Society of America Journal, vol. 69, no. 3, pp. 577-583, 2005.

[44] C. Chen, K. Hu, W. Li, G. Wang, and G. Liu, "Estimating the wet-end section of soil water retention curve by using the dryend section," Soil Science Society of America Journal, vol. 78, no. 6, pp. 1878-1883, 2014.

[45] A. G. Hunt and G. W. Gee, "Water-Retention of fractal soil models using continuum percolation theory: tests of hanford site soils," Vadose Zone Journal, vol. 1, no. 2, pp. 252-260, 2002.

[46] M. H. Mohammadi and M. Vanclooster, "Predicting the soil moisture characteristic curve from particle size distribution with a simple conceptual model," Vadose Zone Journal, vol. 10, no. 2, pp. 594-602, 2011.

[47] D. K. Jensen, M. Tuller, L. W. de Jonge, E. Arthur, and P. Moldrup, "A new two-stage approach to predicting the soil water characteristic from saturation to oven-dryness," Journal of Hydrology, vol. 521, pp. 498-507, 2015.

[48] W. M. Cornelis, J. Ronsyn, M. Van Meirvenne, and R. Hartmann, "Evaluation of pedotransfer functions for predicting the soil moisture retention curve," Soil Science Society of America Journal, vol. 65, no. 3, pp. 638-648, 2001.

[49] L. A. George, M. M. Dewoolkar, and D. Znidarcic, "Simultaneous laboratory measurement of acoustic and hydraulic properties of unsaturated soils," Vadose Zone Journal, vol. 8, no. 3, pp. 633-642, 2009. 
[50] Q. Y. Mu, H. Dong, H. J. Liao, Y. J. Dang, and C. Zhou, "Water-retention curves of loess under wetting-drying cycles," Géotechnique Letters, vol. 10, no. 2, pp. 135-140, 2020.

[51] M. A. Dafalla, A. M. Al-Mahbashi, A. Almajed, and M. AlShamrani, "Predicting soil-water characteristic curves of clayey sand soils using area computation," Mathematical Problems in Engineering, vol. 2020, Article ID 4548912, 9 pages, 2020.

[52] N. R. A. Bird, E. Perrier, and M. Rieu, "The water retention function for a model of soil structure with pore and solid fractal distributions," European Journal of Soil Science, vol. 51, no. 1, pp. 55-63, 2008.

[53] K. M. A. Al Haj and J. R. Standing, "Soil water retention curves representing two tropical clay soils from Sudan," Géotechnique, vol. 66, no. 1, pp. 71-84, 2016.

[54] E. Romero, G. Della Vecchia, and C. Jommi, "An insight into the water retention properties of compacted clayey soils," Géotechnique, vol. 61, no. 4, pp. 313-328, 2011.

[55] D. Sun, Z. Zhang, Y. Gao, and B. Chen, "Determination of basic parameters of swcc for clayer soils," Journal of Shanghai University (Natural Science), vol. 25, no. 6, pp. 957-964, 2019.

[56] E. C. Leong and H. Rahardjo, "Review of soil-water characteristic curve equations," Journal of Geotechnical and Geoenvironmental Engineering, vol. 123, no. 12, pp. 1106-1117, 1997.

[57] M. D. Fredlund, G. W. Wilson, and D. G. Fredlund, "Use of the grain-size distribution for estimation of the soil-water characteristic curve," Canadian Geotechnical Journal, vol. 39, no. 5, pp. 1103-1117, 2002.

[58] X. W. Ren and J. C. Santamarina, "The hydraulic conductivity of sediments: a pore size perspective," Engineering Geology, vol. 233, pp. 48-54, 2018.

[59] X. Ren, Y. Zhao, Q. Deng, J. Kang, D. Li, and D. Wang, “A relation of hydraulic conductivity - void ratio for soils based on kozeny-carman equation," Engineering Geology, vol. 213, pp. 89-97, 2016.

[60] H. Rahardjo, A. Satyanaga, H. Mohamed, S. C. Yee Ip, and R. S. Shah, "Comparison of soil-water characteristic curves from conventional testing and combination of small-scale centrifuge and dew point methods," Geotechnical and Geological Engineering, vol. 37, no. 2, pp. 659-672, 2019.

[61] R. Gardner, "A method of measuring the capillary tension of soil moisture over a wide moisture range," Soil Science, vol. 43, no. 4, pp. 277-284, 1937.

[62] C. Feuerharmel, W. Y. Y. Gehling, and A. V. D. Bica, “The use of filter-paper and suction-plate methods for determining the soil-water characteristic curve of undisturbed colluvium soils," Geotechnical Testing Journal, vol. 29, no. 5, pp. 419-425, 2006.

[63] S. S. Agus and T. Schanz, "Comparison of four methods for measuring total suction," Vadose Zone Journal, vol. 4, no. 4, pp. 1087-1095, 2005.

[64] F. A. M. Marinho and O. M. Oliveira, "The filter paper method revisited," Geotechnical Testing Journal, vol. 29, no. 3, pp. 250-258, 2006.

[65] R. Fawcett and N. Collis-George, "A filter-paper method for determining the moisture characteristics of soil," Australian Journal of Experimental Agriculture, vol. 7, no. 25, pp. 162167, 1967.

[66] D. Tang, D. Q. Li, H. B. Kim, and E. Ganju, "Research on calibration curves of home-made "double circle" filter papers," Engineering Journal of Wuhan University, vol. 49, no. 1, pp. 1-8, 2016.
[67] F. Bai, S. Liu, and J. Yuan, "Calibration test for total suction wetting curve of filter paper," Rock and Soil Mechanics, vol. 32, no. 8, pp. 2336-2340, 2011.

[68] Z. Wang, J. X. Yang, J. J. Kuang, J. Y. An, and Y. D. Luo, "Application of filter paper method in field measurement of matric suction," Chinese Journal of Geotechnical Engineering, vol. 25, no. 4, pp. 405-408, 2003.

[69] S. L. Houston, W. N. Houston, and A. M. Wagner, "Laboratory filter-paper suction measurements," Geotechnical Testing Journal, vol. 17, no. 2, pp. 185-194, 1994.

[70] E. C. Leong, L. He, and H. Rahardjo, "Factors affecting the filter paper method for total and matric suction measurements," Geotechnical Testing Journal, vol. 25, no. 3, pp. 322-333, 2002.

[71] J. A. Munoz-Castelblanco, J. M. Pereira, P. Delage, and Y. J. Cui, "The water retention properties of a natural unsaturated loess from northern France," Géotechnique, vol. 62, no. 2, pp. 95-106, 2012. 